\title{
L-Phenylalanine Applications and Culture Duration Affect Root Growth and Production of Tropane Alkaloids and Phenolics in Adventitious Root Cultures of Hyoscyamus Niger L.
}

\section{Tunhan DEMIRCI ( $\square$ tunhandemirci@sdu.edu.tr)}

Suleyman Demirel Universitesi https://orcid.org/0000-0001-8516-911X

illknur Albayrak

Isparta Uygulamali Bilimler Universitesi

Nilgün Göktürk Baydar

Isparta Uygulamali Bilimler Universitesi

\section{Research Article}

Keywords: Hyoscyamus niger, adventitious root culture, L-phenylalanine, culture duration, tropane alkaloids, phenolics

Posted Date: June 28th, 2021

DOI: https://doi.org/10.21203/rs.3.rs-400961/v1

License: (c) (1) This work is licensed under a Creative Commons Attribution 4.0 International License. Read Full License

Version of Record: A version of this preprint was published at Plant Cell, Tissue and Organ Culture (PCTOC) on September 16th, 2021. See the published version at https://doi.org/10.1007/s11240-02102173-5. 


\section{Abstract}

This study was aimed to determine the effects of different concentrations of L-phenylalanine $(0.25,0.50$ and $1.00 \mathrm{mM} \mathrm{L-Phe)}$ applied to adventitious root cultures for different culture durations on root growth and production of tropane alkaloids and phenolics in Hyoscyamus niger. For this purpose, adventitious roots obtained from petiole explants of in vitro seedlings were used as plant materials. After adventitious roots were cultured in liquid MS medium, L-Phe was applied to the adventitious roots. Then the roots were harvested on the 1st, 3rd, and 7th day of the applications, fresh and dry root weights, root growth indexes were analysed. It was also examined the contents of tropane alkaloids (hyoscyamine and scopolamine) and phenolics (gallic acid, catechin, epicatechin, vanillin, cinnamic acid, rosmarinic acid, p-coumaric, ocoumaric acid, rutin, caffeic acid, ferulic acid, chlorogenic acid, and quercetin) by HPLC in both adventitious roots and culture medium. As a result, the greatest root growth values were obtained from the roots harvested on the 3rd and 7th days after 0.50 and $1.00 \mathrm{mM} \mathrm{L-Phe} \mathrm{applications.} \mathrm{The} \mathrm{maximum}$ scopolamine and hyoscyamine amounts were detected in the cultures with the application of $0.50 \mathrm{mM} \mathrm{L-}$ Phe for 3 days. In terms of phenolics, $0.50 \mathrm{mM}$ and $1.00 \mathrm{mM}$ L-Phe application with 1 st and 3rd days were selected as the most appropriate L-Phe applications and culture duration. Consequently, it has been determined that in vitro secondary metabolite production may be increased in $\mathrm{H}$. niger root cultures with the selection of appropriate L-Phe concentrations and culture durations.

\section{Introduction}

Hyoscyamus niger L. is a species belonging to the Solanaceae family, which contains very important tropane alkaloids such as hyoscyamine, apohyoscine, apohyoscine, scopolamine, skimmianine, apoatropine, a-belladonnine, b-belladonnine, and tropine. The most important and most abundant ones in H. niger roots are hyoscyamine and scopolamine (Al-Snafi 2018). Hyoscyamine and scopolamine use in the treatment of stomach pain, ulcer, kidney, and liver diseases due to their pain-relieving and spasmresolving effects (John et al. 2010). The economic values of these metabolites are quite high since they have important biological activities, and are found in very low amount in plants. The long and complexity of the biosynthesis pathways make it difficult to the obtaining of these alkaloids synthetically, economically and practically, so the use of wild-collected plants for getting these alkaloids remains a common method today (Dehghan et al. 2012). However, the continuous collection of plants, especially those containing root-derived metabolites, brings with it the danger of extinction. Besides, the infestation of plants by microorganisms, plant production dependent on the seasons, lack of pure and standard plant material, geographical difficulties, and ecological differences prevent the secondary metabolite production of standard quality by collecting from nature (Dörnenburg and Knorr 1997).

In vitro secondary metabolite production techniques create an important potential day by day; to eliminate all the negativities in traditional secondary metabolite isolation by wild-collected plants (Jones et al. 2009). Besides, in vitro secondary metabolite production enables many applications that cannot be applied in nature to be carried out within in vitro conditions to increase the metabolite efficiency to much higher levels. Changes in culture medium, conditions, application of biotic and abiotic elicitors, as well as 
the addition of precursors or intermediates in the biosynthesis pathways are among the approaches that can be applied to increase the in vitro production of commercial metabolites such as alkaloids and phenolics (Demirci et al. 2021; Pitta-Alvarez et al. 2000).

In H. niger, few studies have been conducted to increase the synthesis of tropane alkaloids with in vitro conditions, and all these studies focused on the callus, cell suspension cultures or in vitro plantlets (Aljibouri et al. 2012; Ghorbanpour et al. 2013a, 2013b). However, in vitro root cultures in many plant species containing root-derived metabolites such as $H$. niger are used effectively to produce many metabolites, including tropane alkaloids and phenolics (Moharrami et al. 2017).

L-Phe, is an aromatic amino acid, commence the biosynthesis of various compounds produced from the pathways of phenylpropanoid and flavonoid in cells. A small number of previous studies have stated that L-Phe can increase secondary metabolite production as an inexpensive and effective application for in vitro conditions (Demirci et al. 2020, 2021; Koca and Karaman 2015). It is known that the biosynthesis of hyoscyamine and scopolamine is initiated by the transformation of L-Phe to phenylpyruvate with aromatic amino acid aminotransferase (Bedewitz et al. 2014). Many studies have included applications that generally create stress signals in plants to increase the production of hyoscyamine and scopolamine (Ghorbanpour et al. 2013a; Hong et al. 2012). However, studies on precursors in the biosynthesis pathway of tropane alkaloids are almost non-existent. For this reason, L-Phe was used as a precursor in this research to increase tropane alkaloids and phenolics in adventitious root cultures. The culture duration is an important criterion that changes the amount of metabolite yield for in vitro secondary metabolite production (Shakeran et al. 2015). So determining the most appropriate culture duration is of great importance in terms of obtaining high metabolite yield.

This study, it was aimed to determine the effects of L-Phe application at different concentrations and culture duration on the root growth development, accumulation of tropane alkaloids and phenolics. In addition, phenylalanine ammonia lyase (PAL) activity was also determined to clarify how the applications made changed PAL activity and to reveal the relationship between PAL activity and secondary metabolite production. With this study, L-phenylalanine was used for the first time to increase the yield in the production of hyoscyamine and scopolamine from in vitro $\mathrm{H}$. niger root cultures. It provides important information for future work.

\section{Method}

\section{Plant material}

In this study, adventitious roots derived from petiole explants of in vitro seedlings of $H$. niger were used as plant materials. The seeds were obtained from Zeytinburnu Municipality Medicinal and Aromatic Plants Garden Directorate, Istanbul, Turkey.

\section{Obtaining adventitious root cultures}


In order to overcome dormancy and initiate germination, seeds were kept in $250 \mathrm{mg} \mathrm{I}^{-1}$ gibberellic acid $\left(\mathrm{GA}_{3}\right.$, Sigma-Aldrich, Germany) solution for $48 \mathrm{~h}$ before being transferred to the culture medium (Ghorbanpour et al. 2013b). After $\mathrm{GA}_{3}$ application, seeds were rinsed 4 times with double distilled water $\left(\mathrm{ddH}_{2} \mathrm{O}\right)$ and mixed with $70 \%$ ethyl alcohol (\%99, Tekkim, Turkey) for $10 \mathrm{~s}$. Then seeds were sterilized with $0.1 \%$ mercury chloride $\left(\mathrm{HgCl}_{2}\right.$, Sigma-Aldrich, Germany) solution containing a few drops Tween 20 (Sigma-Aldrich, Germany) for $10 \mathrm{~min}$. Finally, they were rinsed 4 times with sterile $\mathrm{ddH}_{2} \mathrm{O}$ and transferred to a germination medium (Aljibouri et al. 2012).

Murashige and Skoog (MS) medium (Duchefa Biochemie, Netherland) containing $30 \mathrm{~g} \mathrm{~L}^{-1}$ sucrose (Sigma-Aldrich, Germany) and $6 \mathrm{~g} \mathrm{I}^{-1}$ agar (Sigma-Aldrich, Germany) were used for the germination of seeds (Murashige and Skoog 1962). Ten seeds were transferred to each of the sterile Petri dishes containing $30 \mathrm{ml}$ of MS medium and cultured for 15 days at $25^{\circ} \mathrm{C}$ in the dark (Fig. 1-A) (Aljibouri et al. 2012). After the 15-day germination period, the plantlets that emerged from the seed were transferred to $50 \mathrm{ml}$ of the same medium in $250 \mathrm{ml}$ flasks. Then they were grown for 15 more days in a photoperiod of $16 \mathrm{~h}$ light / $8 \mathrm{~h}$ dark, $50 \mu \mathrm{mol} / \mathrm{m}^{2}$ fluorescent light intensity at $25^{\circ} \mathrm{C}$. The petiole segments of $1 \mathrm{~cm}$ length cut with a sterile scalpel from the plantlets were transferred to MS medium containing $2 \mathrm{mg} \mathrm{I}^{-1}$ Indole-3butyric acid (IBA, Sigma-Aldrich, Germany), $30 \mathrm{~g} \mathrm{I}^{-1}$ sucrose, $6 \mathrm{~g} \mathrm{I}^{-1}$ agar and were cultured for 6 weeks at $25^{\circ} \mathrm{C}$ for adventitious root formation (Fig. 1-B, 1-C) (Hong et al. 2012). To reproduce the adventitious roots formed at the end of six weeks, they were transferred to $30 \mathrm{ml}$ liquid MS mediums containing $2 \mathrm{mg} \mathrm{I}^{-1}$ Indole-3-butyric acid and $30 \mathrm{~g} \mathrm{I}^{-1}$ sucrose in $100 \mathrm{ml}$ Erlenmeyer (Fig. 1-D). Liquid root cultures were grown at $25^{\circ} \mathrm{C}$, dark conditions, on an orbital shaker at $90 \mathrm{rpm}$ rotational speed for 3 week periods. Subculture was applied 3 times at 3-week intervals.

\section{L-Phe applications}

Roots propagated in liquid MS medium were weighed 1.5 grams in sterile conditions with the help of analytical scales and transferred to another liquid MS medium containing $0.5 \mathrm{mg} \mathrm{I}^{-1}$ IBA and $30 \mathrm{~g} \mathrm{I}^{-1}$ sucrose. After culturing at $25^{\circ} \mathrm{C}$ for 3 weeks, the roots were used in the L-Phe (Sigma-Aldrich, Germany) applications. The stock solution of L-Phe was prepared with distilled water and filter-sterilized. Then LPhe at $0.25,0.50$, and $1.00 \mathrm{mM}$ concentrations were added to the medium with $3 \%$ Tween-20 which has been reported to have positive effects on the accumulation of tropane alkaloids (Boitel-Conti et al. 2000). To the control group, only tween 20 was added. A completely randomized design was used during the applications and analysis ( 4 application $\times 3$ replication $\times 4$ flasks). Adventitious roots were harvested on the $1 \mathrm{st}$, 3rd and 7th days after the applications. At the harvest, culture mediums were transferred to amber bottles and stored at $-20^{\circ} \mathrm{C}$ and adventitious roots were reserved for later analysis.

\section{Determination of root growth parameters}

Roots, harvested on the 1st, 3rd and 7th days, were washed with $\mathrm{ddH}_{2} \mathrm{O}$ and excess water was removed with blotting paper. Then fresh weights of adventitious roots were weighted with analytical scales and

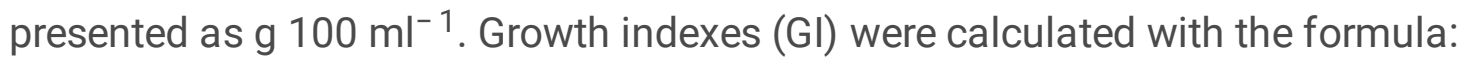


GI: (harvested FW (g) - inoculated FW (g)) / inoculated FW (g)

Then roots were dried at $40^{\circ} \mathrm{C}$ for $72 \mathrm{~h}$ and weighted with the help of an analytical balance. The dried roots weights were expressed as g $100 \mathrm{ml}^{-1}$.

\section{Extraction of tropan alkaloids and phenolics from adventitious roots and culture medium}

For the extraction from adventitious roots, completely dried roots were powdered with the help of mortar and pestle. Then, $200 \mathrm{mg}$ of powdered roots were extracted with $20 \mathrm{ml}$ of methanol (HPLC grade, Sigma Aldrich, Germany) - $\mathrm{dd}_{2} \mathrm{O}(60: 40(\mathrm{v} / \mathrm{v}))$ solution in an ultrasonic water bath for $15 \mathrm{~min}$. After the mixture was centrifuged at $10.000 \mathrm{rpm}$ for $15 \mathrm{~min}$, the liquid fraction was collected in a separate test tube. The same processes were repeated twice by adding $20 \mathrm{ml}$ of methanol- $\mathrm{ddH}_{2} \mathrm{O}$ mixture to the pelleted part again. The liquid fractions were combined and evaporated under pressure at $45^{\circ} \mathrm{C}$ with the aid of a rotary evaporator to obtain dry extracts. After evaporation, dried extracts were dissolved in $1.5 \mathrm{ml}$ pure methanol and passed through $0.45 \mu \mathrm{m}$ filters and stored at $-20^{\circ} \mathrm{C}$ until used in the analysis.

The extraction of tropane alkaloids from the culture mediums was done according to the method of Boitel-Conti et al. (2000). Accordingly, after adding $3 \mathrm{ml}$ of $28 \%$ ammonium hydroxide $\left(\mathrm{NH}_{4} \mathrm{OH}\right.$, SigmaAldrich, Germany) to $40 \mathrm{ml}$ of filtered culture medium, the alkaloids were extracted 3 times with $30 \mathrm{ml}$ of chloroform. Then, chloroform was removed in a rotary evaporator and the residue was dissolved with 2 $\mathrm{ml}$ of methanol After filtration, extracts were used in HPLC analysis.

The phenolic contents in the culture medium were performed according to the method of Vuong et al. (2014). Shortly, $10 \mathrm{ml}$ of $100 \%$ ethyl acetate was added to $10 \mathrm{ml}$ of culture medium and mixed rapidly for $5 \mathrm{~min}$. The mixture was kept immobile for $30 \mathrm{~min}$ at room temperature, allowing the ethyl acetate phase to be separated from the culture medium. Then, the phase was stored in a separate bottle. The same process was repeated two more times by adding ethyl acetate into the culture medium. After the extraction process was completed, the ethyl acetate was completely evaporated. The residue was then dissolved in $1.5 \mathrm{ml}$ methanol and filtered by $0.45 \mu \mathrm{m}$ pore size membrane filters (Millipore Co. Bedford, MA), and then used in HPLC analysis.

\section{Determination of tropane alkaloids and phenolics by HPLC}

In order to detect tropan alkaloids, an HPLC system manufactured by Shimadzu Corp. (Kyoto, Japan) was used. The separation of hyoscyamine and scopolamine was carried out by Agilent Eclipse XDB-C18 HPLC column $(250 \times 4.6 \mathrm{~mm}$ i.d. $5 \mu \mathrm{m}$, Wellborn, Germany). In the separation process performed with the gradient program at $0.8 \mathrm{ml} \mathrm{min}^{-1}$ flow rate, the injection volume was $20 \mu \mathrm{l}$, the column temperature was set at $40^{\circ} \mathrm{C}, 2 \%$ acetic acid (mobile phase A, HPLC grade, Sigma-Aldrich) and $100 \%$ acetonitrile (mobile phase B, HPLC, Sigma-Aldrich) were used according to modify the method by Boitel-Conti et al. (2000). The gradient program was as follows; $0-12 \mathrm{~min}, 0-12 \% \mathrm{~B} ; 12-13 \mathrm{~min}, 12-20 \% \mathrm{~B} ; 13-33 \mathrm{~min}, 20-28 \% \mathrm{~B}$; 33-48 min, 28-100\% B. Scopolamine and hyoscyamine analytical standards obtained from Sigma- 
Aldrich were prepared in different dilutions and run by HPLC. The correlation coefficient $\left(R^{2}\right)$ for scopolamine was found to be 0.9887 and for hyoscyamine 0.9981 . The results of HPLC runs on roots and culture mediums were calculated as $\mathrm{mg} \mathrm{g}^{-1}$ dry root weight, $\mathrm{mg} 100 \mathrm{ml}^{-1}$ in culture mediums and mg per flask.

The amounts of gallic acid, catechin, chlorogenic acid, caffeic acid, epicatechin, vanillin, rosmarinic acid, p-coumaric acid, o-coumaric acid, ferulic acid, rutin, cinnamic acid and quercetin in root and culture medium were determined by the same HPLC system and conditions. The gradient elution; mobile phase A contained $2 \%$ Acedic acid (HPLC, Sigma-Aldrich), solvent B contained Methanol (HPLC, Sigma-Aldrich). The following gradient was used: $0-12 \mathrm{~min}, 0-12 \% \mathrm{~B} ; 12-13 \mathrm{~min}, 12-20 \% \mathrm{~B} ; 13-33 \mathrm{~min}, 20-28 \% \mathrm{~B}$; 33-48 min, 28-30\% B; 48-53 min, 30-38\% B; 53-68 min, 38-40\% B; 68-70 min, 40\% B; 70-90 min, 40-50\% B; 90-105 min, 50-60\% B; 105-107 min, 60-100\% B; 107-112 min, 100\% B; 112-117 min, 0\% $B$ (Demirci et al. 2021). During the determination of the amounts of phenolics by HPLC, analytical standards obtained from Sigma-Aldrich were used. The standards were prepared in different dilutions and

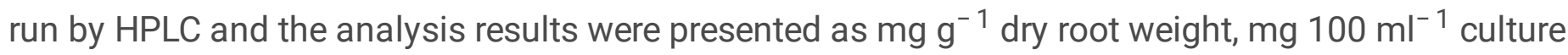
medium, and mg per flask according to analytical standards.

For HPLC calculation of tropane alkaloids and phenolics, scopolamine and hyoscyamine examined at $220 \mathrm{~nm}$; gallic acid, catechin, epicatechin, vanillin, rosmarinic acid, cinnamic acid, and o-coumaric acid at $278 \mathrm{~nm}$; p-coumaric acid at $309 \mathrm{~nm}$; caffeic acid and ferulic acid at $320 \mathrm{~nm}$; chlorogenic acid at $325 \mathrm{~nm}$; routine and quercetin at $370 \mathrm{~nm}$ (Supplementary Material 1). HPLC was run on all flasks at least 2 times to examine the amounts of tropane alkaloids and phenolics in adventitious roots, culture medium and per flask (4 application $\times 3$ replication $\times 4$ flasks $\times 2$ runs). HPLC data were calculated with Shimadzu ClassVP Chromatography Laboratory Automatic Software System.

\section{Determination of total phenolic content (TPC)}

TPCs of the adventitious roots and culture medium were determined using Folin-Ciocalteu method (Singleton and Rossi 1965). The absorbances of the extracts were measured at $765 \mathrm{~nm}$ by a T70 Plus Dual Beam spectrophotometer. Total phenolic contents in adventitious roots and culture medium were calculated by the calibration curve prepared according to the gallic acid analytical standard.

\section{Determination of phenylalanine ammonia lyase (PAL) activity}

For the analysis of PAL activity, $0.5 \mathrm{~g}$ of fresh adventitious roots were extracted in $50 \mathrm{mM}$ K-phosphate buffer $(\mathrm{pH}=7)$ containing $1.0 \mathrm{mM}$ EDTA and $1 \%$ polyvinylpyrrolidone. The supernatant of the enzyme extract, which was centrifuged at $10,000 \times \mathrm{g}$ for $15 \mathrm{~min}$ at $4^{\circ} \mathrm{C}$, was collected for analyses. The determination of PAL enzyme activity was carried out according to the method of D'Cunha et al. (1996). Absorbances at $290 \mathrm{~nm}$ were determined as a measure of trans-cinnamic acid produced.

\section{Statistical analyses}


Data were subjected to analysis of variance with mean separation by Duncan's multiple range tests. Differences were considered statistically significant at the $p \leq 0.05$ levels.

\section{Results}

\section{Effects on the roots growth parameters}

The effects of L-Phe applied to H. niger adventitious root cultures at different concentration and duration on fresh root weight, root growth index and dry root weight were examined, and the results are presented in Fig. 2. As a result of the variance analysis on the root growth parameters, it was found that the interactions of application*culture duration were not statistically significant. On the other hand, when the applications and culture duration were examined separately, there were significant differences $(p \leq 0.05)$. It was determined that as L-Phe concentration and culture duration increased, root growth parameters parallelly increased. The greatest values of fresh root weights $\left(11.33-11.64 \mathrm{~g} 100 \mathrm{ml}^{-1}\right)$, growth indexes (1.27-1.33) and dry root weights (1.08-1.11 $\left.\mathrm{g} 100 \mathrm{ml}^{-1}\right)$ were obtained from the roots applied with 0.50 $\mathrm{mM}$ and $1.00 \mathrm{mM}$ of L-Phe and harvested at 3rd and 7th days.

\section{Effects on the production of tropane alkaloids}

In order to understand the effects of L-Phe applications and culture durations on the production of tropane alkaloids, the amounts of hyoscyamine and scopolamine were determined. For this, the amount of alkaloids in adventitious roots and in the culture medium were determined separately, and then the amount of alkaloids obtained per flask was calculated. Applications and culture durations interactions were statistically significant $(p \leq 0,05)$, according to scopolamine and hyoscyamine accumulations in adventitious roots, culture medium, and per flask (Supplementary Material 2). When the scopolamine amounts were examined, it was seen that the amount of scopolamine increased in parallel with the dose with 0.25 and $0.50 \mathrm{mM} \mathrm{L-Phe} \mathrm{applications} \mathrm{both} \mathrm{in} \mathrm{the} \mathrm{roots,} \mathrm{in} \mathrm{the} \mathrm{culture} \mathrm{medium} \mathrm{and} \mathrm{in} \mathrm{the} \mathrm{production}$ amount per flask (Fig. 3). However, there was a decrease in the upward trend in scopolamine production with $1.00 \mathrm{mM}$ L-Phe. Scopolamine was mostly obtained in adventitious roots with $0.50 \mathrm{mM}$ L-Phe as 1.96 and $1.97 \mathrm{mg} \mathrm{g}^{-1}$ on the $1 \mathrm{st}$ and 3rd days, respectively, and 6.12 times more in the control group. Similarly, it was determined that the amount of scopolamine with $0.50 \mathrm{mM}$ L-Phe in the culture medium was higher than the other groups, and there was approximately 1.5 times more scopolamine. When the quantities of scopolamine produced per flask were calculated, the highest amounts were again obtained with $0.50 \mathrm{mM}$ L-Phe.

Hyoscyamine accumulation occurred similarly to scopolamine (Fig. 4). In adventitious roots, the highest hyoscyamine was obtained with $0.50 \mathrm{mM} \mathrm{L-Phe} \mathrm{as} 0.59 \mathrm{mg} \mathrm{g}^{-1}$ on the 3 rd day. Approximately 2 times more hyoscyamine was produced compared to control roots. This amount decreased statistically significantly when the culture duration was extended. The amount of hyoscyamine in the culture medium was statistically higher than the other groups at $0.25 \mathrm{mM} \mathrm{L-Phe} \mathrm{application.} \mathrm{While} \mathrm{culture} \mathrm{duration} \mathrm{did}$ not affect the amount of hyoscyamine in the control group and $1.00 \mathrm{mM}$ L-Phe application, 0.25 and 0.50 
$\mathrm{mM}$ L-Phe applications increased the amount of hyoscyamine compared to the culture duration. The highest amount of hyoscyamine produced per flask was 0.23 and $0.20 \mathrm{mg} \mathrm{flask}^{-1}$ on the 3rd and 7 th days, respectively, with $0.50 \mathrm{mM}$ L-Phe application.

\section{Effects on the production of phenolics}

In this study, changes in phenolic contents in H. niger adventitious root cultures depending on L-Phe applications and culture durations were also investigated. For this purpose, TPC and gallic acid, catechin, epicatechin, vanillin, cinnamic acid, rosmarinic acid, p-coumaric, o-coumaric acid, rutin, caffeic acid, ferulic acid, chlorogenic acid, and quercetin amounts were determined in adventitious roots and culture medium. Rutin, o-coumaric acid and quercetin could not be detected in cultures while amounts of other phenolics were determined according to L-Phe applications and culture duration. In adventitious roots, the effects on the phenolics are presented in Table 1. In terms of TPC and all phenolics except chlorogenic acid, the application*culture duration interactions were statistically significant $(p \leq 0.05)$. In this study, 0.5 and $1.00 \mathrm{mM} \mathrm{L-Phe} \mathrm{applications} \mathrm{and} \mathrm{3-day} \mathrm{culture} \mathrm{duration} \mathrm{had} \mathrm{stimulating} \mathrm{effects} \mathrm{on} \mathrm{the} \mathrm{TPCs} \mathrm{in}$ adventitious roots. While all L-Phe applications increased TPC compared to the control, the lowest value was obtained from the control roots harvested on the 1st day. Accordingly, it was found that the most effective application*culture duration combination in terms of TPC was $0.50 \mathrm{mM}$ L-Phe application for 3 days. According to HPLC results, the phenolic accumulations significantly changed depending on the LPhe applications and culture duration. 
Table 1

Effects of L-Phenylalanine application and culture duration on the phenolic contents of adventitious roots in Hyoscyamus niger (Rutin, o-coumaric acid and quercetin could not be detected)

\begin{tabular}{|c|c|c|c|c|c|}
\hline \multirow[t]{2}{*}{ Phenolics } & \multirow[t]{2}{*}{ Applications } & \multicolumn{4}{|c|}{ Culture duration (days) } \\
\hline & & $1 \mathrm{st}$ & 3rd & 7th & Mean \\
\hline \multirow{5}{*}{$\begin{array}{l}\text { Total phenolic } \\
\text { contents } \\
\left(\mathrm{mg} \mathrm{g}^{-1} \mathrm{DW}\right)\end{array}$} & Control & $5.14 \pm 0.06 \mathrm{Cc}^{\star}$ & $6.85 \pm 0.08 \mathrm{Ac}$ & $5.75 \pm 0.07 \mathrm{Bd}$ & 5.92 \\
\hline & $\begin{array}{l}0.25 \text { mM L- } \\
\text { Phe }\end{array}$ & $7.37 \pm 0.15 \mathrm{Ab}$ & $\begin{array}{l}7.46 \pm 0.12 \\
A b c\end{array}$ & $6.34 \pm 0.03 \mathrm{Bc}$ & 7.06 \\
\hline & $\begin{array}{l}0.50 \mathrm{mM} \mathrm{L}- \\
\text { Phe }\end{array}$ & $7.86 \pm 0.05 \mathrm{Ba}$ & $8.82 \pm 0.23 \mathrm{Aa}$ & $8.10 \pm 0.03 \mathrm{Ba}$ & 7.97 \\
\hline & $\begin{array}{l}1.00 \mathrm{mM} \mathrm{L-} \\
\text { Phe }\end{array}$ & $8.01 \pm 0.08 \mathrm{Aa}$ & $\begin{array}{l}8.13 \pm 0.17 \\
\text { Aab }\end{array}$ & $7.77 \pm 0.03 \mathrm{Ab}$ & 8.26 \\
\hline & Mean & 7.10 & 7.81 & 6.99 & \\
\hline \multirow{5}{*}{$\begin{array}{l}\text { Gallic acid } \\
\left(\mu \mathrm{g} \mathrm{g}^{-1} \mathrm{DW}\right)\end{array}$} & Control & $\begin{array}{l}20.57 \pm 0.01 \\
\mathrm{Bd}\end{array}$ & $\begin{array}{l}24.38 \pm 0.42 \\
\text { Ad }\end{array}$ & $25.31 \pm 0.73 \mathrm{Ac}$ & 23.42 \\
\hline & $\begin{array}{l}0.25 \mathrm{mM} \mathrm{L}- \\
\text { Phe }\end{array}$ & $\begin{array}{l}40.56 \pm 0.47 \\
\text { Ac }\end{array}$ & $\begin{array}{l}38.11 \pm 0.49 \\
\mathrm{Bc}\end{array}$ & $\begin{array}{l}36.27 \pm 0.65 \\
\mathrm{Bb}\end{array}$ & 38.32 \\
\hline & $\begin{array}{l}0.50 \mathrm{mM} \mathrm{L-} \\
\text { Phe }\end{array}$ & $\begin{array}{l}64.67 \pm 0.19 \\
\mathrm{Aa}\end{array}$ & $\begin{array}{l}65.08 \pm 0.24 \\
\mathrm{Aa}\end{array}$ & $\begin{array}{l}54.31 \pm 0.60 \\
\mathrm{Ba}\end{array}$ & 61.36 \\
\hline & $\begin{array}{l}1.00 \mathrm{mM} \mathrm{L-} \\
\text { Phe }\end{array}$ & $\begin{array}{l}45.77 \pm 0.49 \\
A b\end{array}$ & $\begin{array}{l}40.87 \pm 0.18 \\
\mathrm{Bb}\end{array}$ & $\begin{array}{l}37.94 \pm 0.80 \\
\mathrm{Cb}\end{array}$ & 41.53 \\
\hline & Mean & 42.89 & 42.11 & 38.46 & \\
\hline \multirow{5}{*}{$\begin{array}{l}\text { Catechin } \\
\left(\mu \mathrm{g} \mathrm{g}^{-1} \mathrm{DW}\right)\end{array}$} & Control & $\begin{array}{l}162.69 \pm 1.9 \\
\mathrm{Bd}\end{array}$ & $\begin{array}{l}227.02 \pm 3.3 \\
\text { Ad }\end{array}$ & $\begin{array}{l}220.60 \pm 0.4 \\
\mathrm{Ab}\end{array}$ & 203.44 \\
\hline & $\begin{array}{l}0.25 \mathrm{mM} \mathrm{L-} \\
\text { Phe }\end{array}$ & $\begin{array}{l}773.28 \pm 3.6 \\
A b\end{array}$ & $\begin{array}{l}358.47 \pm 30.5 \\
\mathrm{BC}\end{array}$ & $\begin{array}{l}244.61 \pm 11.7 \\
\mathrm{Cb}\end{array}$ & 458.79 \\
\hline & $\begin{array}{l}0.50 \mathrm{mM} \mathrm{L-} \\
\text { Phe }\end{array}$ & $\begin{array}{l}626.96 \pm 24.8 \\
\text { Cc }\end{array}$ & $\begin{array}{l}903.88 \pm 34.8 \\
\mathrm{Aa}\end{array}$ & $\begin{array}{l}788.52 \pm 1.2 \\
\mathrm{Ba}\end{array}$ & 773.12 \\
\hline & $\begin{array}{l}1.00 \mathrm{mM} \mathrm{L-} \\
\text { Phe }\end{array}$ & $\begin{array}{l}863.45 \pm 27.4 \\
\mathrm{Aa}\end{array}$ & $\begin{array}{l}670.16 \pm 7.3 \\
\mathrm{Bb}\end{array}$ & $176.99 \pm 6.2 \mathrm{Cc}$ & 570.20 \\
\hline & Mean & 606.59 & 539.88 & 357.68 & \\
\hline \multirow{2}{*}{$\begin{array}{l}\text { Epicatechin } \\
\left(\mu \mathrm{g} \mathrm{g}^{-1} \mathrm{DW}\right)\end{array}$} & Control & $\begin{array}{l}16.24 \pm 0.54 \\
C d\end{array}$ & $\begin{array}{l}28.18 \pm 0.43 \\
\mathrm{Bd}\end{array}$ & $\begin{array}{l}35.94 \pm 1.95 \\
A b\end{array}$ & 26.79 \\
\hline & $\begin{array}{l}0.25 \mathrm{mM} \mathrm{L-} \\
\text { Phe }\end{array}$ & $\begin{array}{l}26.03 \pm 1.12 \\
\text { Cc }\end{array}$ & $\begin{array}{l}39.74 \pm 0.46 \\
\text { Ac }\end{array}$ & $\begin{array}{l}34.51 \pm 1.03 \\
\mathrm{Bb}\end{array}$ & 33.43 \\
\hline
\end{tabular}

* Different capital letters within the same row show significant differences between culture durations by Duncan test $(p \leq 0.05)$. Different small letters within the same column show significant differences between L-Phe applications by Duncan test $(p \leq 0.05)$. 


\begin{tabular}{|c|c|c|c|c|c|}
\hline \multirow[t]{2}{*}{ Phenolics } & \multirow[t]{2}{*}{ Applications } & \multicolumn{4}{|c|}{ Culture duration (days) } \\
\hline & & 1st & 3rd & 7th & Mean \\
\hline & $\begin{array}{l}0.50 \mathrm{mM} \mathrm{L-} \\
\text { Phe }\end{array}$ & $\begin{array}{l}67.35 \pm 24.8 \\
\mathrm{Ba}\end{array}$ & $\begin{array}{l}87.93 \pm 0.56 \\
\mathrm{Aa}\end{array}$ & $\begin{array}{l}87.41 \pm 0.98 \\
\mathrm{Aa}\end{array}$ & 80.90 \\
\hline & $\begin{array}{l}1.00 \mathrm{mM} \mathrm{L-} \\
\text { Phe }\end{array}$ & $\begin{array}{l}40.68 \pm 0.77 \\
A b\end{array}$ & $\begin{array}{l}42.37 \pm 0.28 \\
\mathrm{Ab}\end{array}$ & $\begin{array}{l}30.52 \pm 0.68 \\
\mathrm{Bb}\end{array}$ & 37.85 \\
\hline & Mean & 37.57 & 49.55 & 47.09 & \\
\hline \multirow{5}{*}{$\begin{array}{l}\text { Vanillin } \\
\left(\mu \mathrm{g} \mathrm{g}^{-1} \mathrm{DW}\right)\end{array}$} & Control & $9.72 \pm 0.63 \mathrm{Ac}$ & $9.43 \pm 0.76 \mathrm{Ac}$ & $9.67 \pm 0.18 \mathrm{Ad}$ & 9.61 \\
\hline & $\begin{array}{l}0.25 \mathrm{mM} \mathrm{L-} \\
\text { Phe }\end{array}$ & $\begin{array}{l}12.02 \pm 0.06 \\
\mathrm{Bb}\end{array}$ & $\begin{array}{l}15.18 \pm 0.95 \\
A b\end{array}$ & $\begin{array}{l}16.43 \pm 0.31 \\
\mathrm{Ab}\end{array}$ & 14.54 \\
\hline & $\begin{array}{l}0.50 \text { mM L- } \\
\text { Phe }\end{array}$ & $\begin{array}{l}22.38 \pm 0.04 \\
\mathrm{Ba}\end{array}$ & $\begin{array}{l}27.99 \pm 1.35 \\
\mathrm{Aa}\end{array}$ & $\begin{array}{l}24.63 \pm 0.29 \\
\text { ABa }\end{array}$ & 25.00 \\
\hline & $\begin{array}{l}1.00 \mathrm{mM} \mathrm{L-} \\
\text { Phe }\end{array}$ & $\begin{array}{l}11.96 \pm 0.06 \\
\mathrm{Cb}\end{array}$ & $\begin{array}{l}13.52 \pm 0.10 \\
\text { Abc }\end{array}$ & $12.82 \pm 0.21 \mathrm{Bc}$ & 12.77 \\
\hline & Mean & 14.02 & 16.53 & 15.89 & \\
\hline \multirow{5}{*}{$\begin{array}{l}\text { Cinnamic acid } \\
\left(\mu \mathrm{g} \mathrm{g}^{-1} \mathrm{DW}\right)\end{array}$} & Control & $3.18 \pm 0.58 \mathrm{Ad}$ & $4.22 \pm 0.11 \mathrm{Ac}$ & $3.84 \pm 0.01 \mathrm{Ab}$ & 3.74 \\
\hline & $\begin{array}{l}0.25 \mathrm{mM} \mathrm{L-} \\
\text { Phe }\end{array}$ & $6.42 \pm 0.43 \mathrm{Bc}$ & $\begin{array}{l}11.32 \pm 0.29 \\
A b\end{array}$ & $\begin{array}{l}10.57 \pm 0.67 \\
\mathrm{Ba}\end{array}$ & 9.43 \\
\hline & $\begin{array}{l}0.50 \mathrm{mM} \mathrm{L}- \\
\text { Phe }\end{array}$ & $9.44 \pm 0.25 \mathrm{Ab}$ & $\begin{array}{l}10.49 \pm 0.41 \\
\mathrm{Ab}\end{array}$ & $9.27 \pm 0.23 \mathrm{Aa}$ & 9.73 \\
\hline & $\begin{array}{l}1.00 \text { mM L- } \\
\text { Phe }\end{array}$ & $\begin{array}{l}14.37 \pm 0.07 \\
\text { Aa }\end{array}$ & $\begin{array}{l}14.37 \pm 0.26 \\
\mathrm{Aa}\end{array}$ & $\begin{array}{l}10.08 \pm 0.21 \\
\mathrm{Ba}\end{array}$ & 12.94 \\
\hline & Mean & 8.35 & 10.10 & 8.44 & \\
\hline \multirow{5}{*}{$\begin{array}{l}\text { Rosmarinic } \\
\text { acid } \\
\left(\mu g^{-1} \mathrm{DW}\right)\end{array}$} & Control & $8.20 \pm 0.06 \mathrm{Cc}$ & $\begin{array}{l}12.80 \pm 0.40 \\
\text { Aab }\end{array}$ & $\begin{array}{l}10.41 \pm 0.53 \\
\mathrm{Bb}\end{array}$ & 10.47 \\
\hline & $\begin{array}{l}0.25 \mathrm{mM} \mathrm{L-} \\
\text { Phe }\end{array}$ & $\begin{array}{l}10.49 \pm 0.70 \\
\mathrm{Bbc}\end{array}$ & $\begin{array}{l}19.30 \pm 2.83 \\
\mathrm{Aa}\end{array}$ & $\begin{array}{l}12.92 \pm 0.10 \\
\text { Aba }\end{array}$ & 14.24 \\
\hline & $\begin{array}{l}0.50 \mathrm{mM} \mathrm{L-} \\
\text { Phe }\end{array}$ & $\begin{array}{l}20.43 \pm 0.93 \\
\mathrm{Aa}\end{array}$ & $\begin{array}{l}10.91 \pm 0.47 \\
\mathrm{Cb}\end{array}$ & $\begin{array}{l}13.88 \pm 0.31 \\
\mathrm{Ba}\end{array}$ & 15.07 \\
\hline & $\begin{array}{l}1.00 \mathrm{mM} \mathrm{L-} \\
\text { Phe }\end{array}$ & $\begin{array}{l}12.98 \pm 0.03 \\
A b\end{array}$ & $\begin{array}{l}12.83 \pm 0.07 \\
\text { Aab }\end{array}$ & $\begin{array}{l}12.76 \pm 0.24 \\
\mathrm{Aa}\end{array}$ & 12.86 \\
\hline & Mean & 13.02 & 13.96 & 12.49 & \\
\hline $\begin{array}{l}p \text {-coumaric } \\
\text { acid }\end{array}$ & Control & $3.34 \pm 0.08 \mathrm{Ac}$ & $3.86 \pm 0.95 \mathrm{Ab}$ & $0.00 \pm 0.00 \mathrm{Bb}$ & 2.40 \\
\hline
\end{tabular}

* Different capital letters within the same row show significant differences between culture durations by Duncan test $(p \leq 0.05)$. Different small letters within the same column show significant differences between L-Phe applications by Duncan test $(p \leq 0.05)$. 


\begin{tabular}{|c|c|c|c|c|c|}
\hline \multirow[t]{2}{*}{ Phenolics } & \multirow[t]{2}{*}{ Applications } & \multicolumn{4}{|c|}{ Culture duration (days) } \\
\hline & & 1st & 3rd & 7th & Mean \\
\hline \multirow[t]{4}{*}{$\left(\mu g^{-1} \mathrm{DW}\right)$} & $\begin{array}{l}0.25 \mathrm{mM} \mathrm{L-} \\
\text { Phe }\end{array}$ & $\begin{array}{l}16.16 \pm \\
0.42 A a b\end{array}$ & $4.33 \pm 0.58 \mathrm{Bb}$ & $0.00 \pm 0.00 \mathrm{Cb}$ & 6.83 \\
\hline & $\begin{array}{l}0.50 \mathrm{mM} \mathrm{L-} \\
\text { Phe }\end{array}$ & $\begin{array}{l}13.32 \pm 0.73 \\
A b\end{array}$ & $\begin{array}{l}10.27 \pm 1.03 \\
\mathrm{Ba}\end{array}$ & $0.00 \pm 0.00 \mathrm{Bb}$ & 7.86 \\
\hline & $\begin{array}{l}1.00 \mathrm{mM} \mathrm{L-} \\
\text { Phe }\end{array}$ & $\begin{array}{l}19.46 \pm 1.38 \\
\mathrm{Aa}\end{array}$ & $9.51 \pm 0.96 \mathrm{Ba}$ & $3.24 \pm 0.21 \mathrm{Ca}$ & 10.74 \\
\hline & Mean & 13.07 & 6.99 & 0.81 & \\
\hline \multirow{5}{*}{$\begin{array}{l}\text { Caffeic acid } \\
\left(\mu g^{-1} \mathrm{DW}\right)\end{array}$} & Control & $0.69 \pm 0.01 \mathrm{Ab}$ & $0.00 \pm 0.00 \mathrm{Ba}$ & $0.00 \pm 0.00 \mathrm{Ba}$ & 0.23 \\
\hline & $\begin{array}{l}0.25 \mathrm{mM} \mathrm{L-} \\
\text { Phe }\end{array}$ & $4.57 \pm 0.07 \mathrm{Aa}$ & $0.00 \pm 0.00 \mathrm{Ba}$ & $0.00 \pm 0.00 \mathrm{Ba}$ & 1.52 \\
\hline & $\begin{array}{l}0.50 \mathrm{mM} \mathrm{L-} \\
\text { Phe }\end{array}$ & $0.36 \pm 0.01 \mathrm{Ac}$ & $0.17 \pm 0.01 \mathrm{Ba}$ & $0.00 \pm 0.00 \mathrm{Ca}$ & 0.17 \\
\hline & $\begin{array}{l}1.00 \mathrm{mM} \mathrm{L-} \\
\text { Phe }\end{array}$ & $0.74 \pm 0.04 \mathrm{Ab}$ & $0.70 \pm 0.35 \mathrm{Aa}$ & $0.00 \pm 0.00 \mathrm{Ba}$ & 0.47 \\
\hline & Mean & 1.59 & 0.22 & 0.00 & \\
\hline \multirow{5}{*}{$\begin{array}{l}\text { Ferulic acid } \\
\left(\mu \mathrm{g} \mathrm{g}^{-1} \mathrm{DW}\right)\end{array}$} & Control & $4.58 \pm 0.37 \mathrm{Aa}$ & $0.15 \pm 0.02 \mathrm{Bc}$ & $0.00 \pm 0.00 \mathrm{Bb}$ & 1.58 \\
\hline & $\begin{array}{l}0.25 \text { mM L- } \\
\text { Phe }\end{array}$ & $\begin{array}{l}2.76 \pm 0.30 \\
A b c\end{array}$ & $0.00 \pm 0.00 \mathrm{Bc}$ & $0.00 \pm 0.00 \mathrm{Bb}$ & 0.92 \\
\hline & $\begin{array}{l}0.50 \mathrm{mM} \mathrm{L-} \\
\text { Phe }\end{array}$ & $1.61 \pm 0.16 \mathrm{Ac}$ & $1.00 \pm 0.20 \mathrm{Ab}$ & $0.00 \pm 0.00 \mathrm{Bb}$ & 0.87 \\
\hline & $\begin{array}{l}1.00 \mathrm{mM} \mathrm{L-} \\
\text { Phe }\end{array}$ & $2.93 \pm 0.17 \mathrm{Ab}$ & $2.35 \pm 0.06 \mathrm{Aa}$ & $1.14 \pm 0.17 \mathrm{Ba}$ & 2.14 \\
\hline & Mean & 2.97 & 0.88 & 0.29 & \\
\hline \multirow{4}{*}{$\begin{array}{l}\text { Chlorogenic } \\
\text { acid } \\
\left(\mu \mathrm{g} \mathrm{g}^{-1} \mathrm{DW}\right)\end{array}$} & Control & $963.91 \pm 26.58$ & $\begin{array}{l}1233.91 \pm \\
33.72\end{array}$ & $1025.95 \pm 4.81$ & $1074.59 \mathrm{c}$ \\
\hline & $\begin{array}{l}0.25 \mathrm{mM} \mathrm{L}- \\
\text { Phe }\end{array}$ & $\begin{array}{l}1364.79 \pm \\
17.95\end{array}$ & $\begin{array}{l}1787.08 \pm \\
58.46\end{array}$ & $1549.57 \pm 5.92$ & $1567.15 b$ \\
\hline & $\begin{array}{l}0.50 \mathrm{mM} \mathrm{L-} \\
\text { Phe }\end{array}$ & $\begin{array}{l}1410.41 \pm \\
30.59\end{array}$ & $\begin{array}{l}1842.83 \pm \\
69.59\end{array}$ & $1690.52 \pm 9.26$ & $\begin{array}{l}1647.92 \\
a b\end{array}$ \\
\hline & $\begin{array}{l}1.00 \mathrm{mM} \mathrm{L-} \\
\text { Phe }\end{array}$ & $\begin{array}{l}1595.09 \pm \\
32.21\end{array}$ & $\begin{array}{l}1887.17 \pm \\
53.14\end{array}$ & $1672.15 \pm 16.7$ & $1718.14 \mathrm{a}$ \\
\hline
\end{tabular}

* Different capital letters within the same row show significant differences between culture durations by Duncan test $(p \leq 0.05)$. Different small letters within the same column show significant differences between L-Phe applications by Duncan test $(p \leq 0.05)$. 


\begin{tabular}{|c|llll|}
\hline Phenolics & Applications & \multicolumn{4}{l}{ Culture duration (days) } & Mean \\
\cline { 2 - 5 } & 1st & 3rd & 7th & Mean \\
\hline Mean & 1333.55 C & $1687.75 \mathrm{~A}$ & $1484.55 \mathrm{~B}$ \\
\hline $\begin{array}{l}\text { * Different capital letters within the same row show significant differences between culture durations } \\
\text { by Duncan test }(\mathrm{p} \leq 0.05) \text {. Different small letters within the same column show significant differences } \\
\text { between L-Phe applications by Duncan test }(p \leq 0.05) \text {. }\end{array}$ \\
\hline
\end{tabular}

The data concerning the effects of L-Phe and culture duration on leakage of phenolics from roots to culture medium were presented in Table 2. Interaction between applications and cultures durations was not found to be significant in terms of TPC. However, $0.5 \mathrm{mM} \mathrm{L}$-Phe and 3rd day were the most affecting L-Phe application and culture duration for TPC in culture medium. When the amounts of other phenolics were examined, phenolics leaking into the culture medium varied depending on the L-Phe concentration. 
Table 2

Effects of L-Phenylalanine (L-Phe) application and culture duration on the phenolics in culture medium (Rutin, $O$-coumaric acid and quercetin could not be detected)

\begin{tabular}{|c|c|c|c|c|c|}
\hline \multirow[t]{2}{*}{ Phenolics } & \multirow[t]{2}{*}{ Applications } & \multicolumn{4}{|c|}{ Culture duration (days) } \\
\hline & & $1 \mathrm{st}$ & 3rd & 7th & Mean \\
\hline \multirow[t]{5}{*}{$\operatorname{TPC}\left(\mathrm{mg} 100 \mathrm{ml}^{-1}\right)$} & Control & $0.86 \pm 0.03^{\star}$ & $1.22 \pm 0.01$ & $0.95 \pm 0.01$ & $1.01 \mathrm{c}$ \\
\hline & $\begin{array}{l}0.25 \mathrm{mM} \mathrm{L-} \\
\text { Phe }\end{array}$ & $1.08 \pm 0.01$ & $1.41 \pm 0.12$ & $1.27 \pm 0.07$ & $1.25 \mathrm{~b}$ \\
\hline & $\begin{array}{l}0.50 \mathrm{mM} \mathrm{L}- \\
\text { Phe }\end{array}$ & $1.27 \pm 0.04$ & $1.53 \pm 0.01$ & $1.36 \pm 0.06$ & $1.38 \mathrm{a}$ \\
\hline & $\begin{array}{l}1.00 \mathrm{mM} \mathrm{L-} \\
\text { Phe }\end{array}$ & $1.15 \pm 0.03$ & $1.32 \pm 0.03$ & $1.20 \pm 0.07$ & $1.22 \mathrm{~b}$ \\
\hline & Mean & $1.09 \mathrm{C}$ & $1.38 \mathrm{~A}$ & $1.19 \mathrm{~B}$ & \\
\hline \multirow[t]{5}{*}{ Gallic acid $\left(\mu \mathrm{g} 100 \mathrm{ml}^{-1}\right)$} & Control & $\begin{array}{l}0.00 \pm 0.00 \\
\text { Ac }\end{array}$ & $\begin{array}{l}0.00 \pm 0.00 \\
\text { Ac }\end{array}$ & $\begin{array}{l}0.00 \pm 0.00 \\
\mathrm{Ad}\end{array}$ & 0.00 \\
\hline & $\begin{array}{l}0.25 \mathrm{mM} \mathrm{L-} \\
\text { Phe }\end{array}$ & $\begin{array}{l}0.00 \pm 0.00 \\
\mathrm{Bc}\end{array}$ & $\begin{array}{l}0.00 \pm 0.00 \\
\mathrm{Bc}\end{array}$ & $\begin{array}{l}11.56 \pm 1.19 \\
A b\end{array}$ & 3.85 \\
\hline & $\begin{array}{l}0.50 \mathrm{mM} \mathrm{L-} \\
\text { Phe }\end{array}$ & $\begin{array}{l}24.23 \pm 0.42 \\
\mathrm{Aa}\end{array}$ & $\begin{array}{l}23.01 \pm 0.47 \\
\mathrm{Aa}\end{array}$ & $\begin{array}{l}20.47 \pm 0.67 \\
\mathrm{Ba}\end{array}$ & 22.57 \\
\hline & $\begin{array}{l}1.00 \mathrm{mM} \mathrm{L-} \\
\text { Phe }\end{array}$ & $\begin{array}{l}4.38 \pm 0.32 \\
A b\end{array}$ & $\begin{array}{l}3.80 \pm 0.14 \\
\mathrm{ABb}\end{array}$ & $\begin{array}{l}3.39 \pm 0.09 \\
\mathrm{BC}\end{array}$ & 3.86 \\
\hline & Mean & 7.15 & 6.70 & 8.85 & \\
\hline \multirow[t]{5}{*}{ Catechin $\left(\mu \mathrm{g} 100 \mathrm{ml}^{-1}\right)$} & Control & $\begin{array}{l}75.16 \pm 5.20 \\
\mathrm{BC}\end{array}$ & $\begin{array}{l}132.04 \pm 6.50 \\
\text { Ac }\end{array}$ & $\begin{array}{l}86.01 \pm 0.34 \\
\text { Bd }\end{array}$ & 98.40 \\
\hline & $\begin{array}{l}0.25 \mathrm{mM} \mathrm{L-} \\
\text { Phe }\end{array}$ & $\begin{array}{l}170.86 \pm \\
0.74 \mathrm{Ba}\end{array}$ & $\begin{array}{l}289.59 \pm 1.99 \\
\mathrm{Aa}\end{array}$ & $\begin{array}{l}123.92 \pm 0.32 \\
\mathrm{Cb}\end{array}$ & 194.79 \\
\hline & $\begin{array}{l}0.50 \mathrm{mM} \mathrm{L}- \\
\text { Phe }\end{array}$ & $\begin{array}{l}108.58 \pm \\
0.34 \mathrm{Cb}\end{array}$ & $\begin{array}{l}224.33 \pm 4.26 \\
A b\end{array}$ & $\begin{array}{l}199.11 \pm 1.01 \\
\mathrm{Ba}\end{array}$ & 177.34 \\
\hline & $\begin{array}{l}1.00 \mathrm{mM} \mathrm{L-} \\
\text { Phe }\end{array}$ & $\begin{array}{l}119.44 \pm \\
3.46 \mathrm{Ab}\end{array}$ & $\begin{array}{l}118.23 \pm 1.91 \\
\text { Ac }\end{array}$ & $\begin{array}{l}97.81 \pm 1.10 \\
\mathrm{BC}\end{array}$ & 111.83 \\
\hline & Mean & 119.01 & 191.05 & 126.72 & \\
\hline \multirow[t]{2}{*}{$\begin{array}{l}\text { Epicatechin }\left(\mu \mathrm{g} 100 \mathrm{ml}^{-}\right. \\
\left.{ }^{-}\right)^{\mathrm{C}}\end{array}$} & Control & $10.15 \pm 0.28$ & $14.59 \pm 0.71$ & $13.18 \pm 0.21$ & $\begin{array}{l}12.64 \\
b\end{array}$ \\
\hline & $\begin{array}{l}0.25 \mathrm{mM} \mathrm{L-} \\
\text { Phe }\end{array}$ & $11.20 \pm 0.13$ & $11.84 \pm 0.86$ & $11.43 \pm 0.54$ & $\begin{array}{l}11.49 \\
b\end{array}$ \\
\hline
\end{tabular}

* Different capital letters within the same row show significant differences between culture durations by Duncan test $(p \leq 0.05)$. Different small letters within the same column show significant differences between L-Phe applications by Duncan test $(p \leq 0.05)$. 


\begin{tabular}{|c|c|c|c|c|c|}
\hline \multirow[t]{2}{*}{ Phenolics } & \multirow[t]{2}{*}{ Applications } & \multicolumn{4}{|c|}{ Culture duration (days) } \\
\hline & & 1st & 3rd & 7th & Mean \\
\hline & $\begin{array}{l}0.50 \mathrm{mM} \mathrm{L}- \\
\text { Phe }\end{array}$ & $31.50 \pm 0.53$ & $42.45 \pm 1.06$ & $33.37 \pm 0.50$ & $\begin{array}{l}35.77 \\
a\end{array}$ \\
\hline & $\begin{array}{l}1.00 \mathrm{mM} \mathrm{L-} \\
\text { Phe }\end{array}$ & $40.19 \pm 1.10$ & $36.43 \pm 0.53$ & $27.02 \pm 22.67$ & $\begin{array}{l}35.54 \\
a\end{array}$ \\
\hline & Mean & 23.26 & 26.33 & 21.25 & \\
\hline \multirow[t]{5}{*}{ Vanillin $\left(\mu \mathrm{g} 100 \mathrm{ml}^{-1}\right)$} & Control & $\begin{array}{l}4.02 \pm 0.41 \\
\mathrm{Bb}\end{array}$ & $\begin{array}{l}5.56 \pm 0.22 \\
A b\end{array}$ & $\begin{array}{l}5.98 \pm 0.33 \\
\mathrm{Ab}\end{array}$ & 5.18 \\
\hline & $\begin{array}{l}0.25 \mathrm{mM} \mathrm{L-} \\
\text { Phe }\end{array}$ & $\begin{array}{l}10.60 \pm 0.73 \\
\mathrm{Aa}\end{array}$ & $\begin{array}{l}12.27 \pm 0.27 \\
\text { Aab }\end{array}$ & $\begin{array}{l}11.51 \pm 0.37 \\
\mathrm{Aa}\end{array}$ & 11.46 \\
\hline & $\begin{array}{l}0.50 \mathrm{mM} \mathrm{L-} \\
\text { Phe }\end{array}$ & $\begin{array}{l}12.45 \pm 0.63 \\
\mathrm{Ba}\end{array}$ & $\begin{array}{l}18.30 \pm 0.31 \\
\mathrm{Aa}\end{array}$ & $\begin{array}{l}12.07 \pm 0.09 \\
\mathrm{Ba}\end{array}$ & 14.27 \\
\hline & $\begin{array}{l}1.00 \mathrm{mM} \mathrm{L-} \\
\text { Phe }\end{array}$ & $\begin{array}{l}9.80 \pm 1.54 \\
\mathrm{Aa}\end{array}$ & $\begin{array}{l}6.74 \pm 3.42 \\
\mathrm{Bb}\end{array}$ & $\begin{array}{l}4.39 \pm 2.19 \\
\mathrm{Cb}\end{array}$ & 6.98 \\
\hline & Mean & 9.21 & 10.72 & 6.98 & \\
\hline \multirow[t]{5}{*}{$\begin{array}{l}\text { Cinnamic acid ( } \mu \mathrm{g} 100 \\
\mathrm{ml}^{-1} \text { ) }\end{array}$} & Control & $\begin{array}{l}0.54 \pm 0.01 \\
\text { Ac }\end{array}$ & $\begin{array}{l}0.47 \pm 0.04 \\
\mathrm{Ab}\end{array}$ & $\begin{array}{l}0.28 \pm 0.01 \\
\mathrm{Bc}\end{array}$ & 0.43 \\
\hline & $\begin{array}{l}0.25 \mathrm{mM} \mathrm{L-} \\
\text { Phe }\end{array}$ & $\begin{array}{l}0.20 \pm 0.01 \\
\text { Cc }\end{array}$ & $\begin{array}{l}0.53 \pm 0.02 \\
\mathrm{Bb}\end{array}$ & $\begin{array}{l}0.95 \pm 0.04 \\
\text { Ac }\end{array}$ & 0.57 \\
\hline & $\begin{array}{l}0.50 \mathrm{mM} \mathrm{L-} \\
\text { Phe }\end{array}$ & $\begin{array}{l}4.34 \pm 0.14 \\
A b\end{array}$ & $\begin{array}{l}6.05 \pm 0.15 \\
\mathrm{Aa}\end{array}$ & $\begin{array}{l}5.56 \pm 0.77 \\
\mathrm{Aa}\end{array}$ & 5.35 \\
\hline & $\begin{array}{l}1.00 \mathrm{mM} \mathrm{L-} \\
\text { Phe }\end{array}$ & $\begin{array}{l}19.87 \pm 0.80 \\
\mathrm{Aa}\end{array}$ & $\begin{array}{l}7.25 \pm 0.52 \\
\mathrm{Ba}\end{array}$ & $\begin{array}{l}2.84 \pm 0.25 \\
\mathrm{Cb}\end{array}$ & 9.99 \\
\hline & Mean & 6.27 & 3.58 & 2.41 & \\
\hline \multirow[t]{5}{*}{$\begin{array}{l}\text { Rosmarinic acid ( } \mu \mathrm{g} 100 \\
\mathrm{ml}^{-1} \text { ) }\end{array}$} & Control & $\begin{array}{l}8.34 \pm 0.09 \\
\text { Ad }\end{array}$ & $\begin{array}{l}7.42 \pm 0.30 \\
\text { Ad }\end{array}$ & $\begin{array}{l}2.96 \pm 0.36 \\
\mathrm{BC}\end{array}$ & 6.24 \\
\hline & $\begin{array}{l}0.25 \mathrm{mM} \mathrm{L-} \\
\text { Phe }\end{array}$ & $\begin{array}{l}14.22 \pm 0.06 \\
\mathrm{Ab}\end{array}$ & $\begin{array}{l}10.50 \pm 0.08 \\
\mathrm{BC}\end{array}$ & $\begin{array}{l}14.30 \pm 0.39 \\
\mathrm{Ab}\end{array}$ & 13.00 \\
\hline & $\begin{array}{l}0.50 \mathrm{mM} \mathrm{L-} \\
\text { Phe }\end{array}$ & $\begin{array}{l}12.55 \pm 0.55 \\
\mathrm{BC}\end{array}$ & $\begin{array}{l}16.58 \pm 0.92 \\
\mathrm{Ab}\end{array}$ & $\begin{array}{l}17.78 \pm 0.97 \\
\mathrm{Aa}\end{array}$ & 15.63 \\
\hline & $\begin{array}{l}1.00 \mathrm{mM} \mathrm{L-} \\
\text { Phe }\end{array}$ & $\begin{array}{l}20.14 \pm 0.08 \\
\mathrm{Aa}\end{array}$ & $\begin{array}{l}21.74 \pm 0.52 \\
\mathrm{Aa}\end{array}$ & $\begin{array}{l}17.84 \pm 0.62 \\
\mathrm{Ba}\end{array}$ & 19.91 \\
\hline & Mean & 13.81 & 14.06 & 13.22 & \\
\hline
\end{tabular}

* Different capital letters within the same row show significant differences between culture durations by Duncan test $(p \leq 0.05)$. Different small letters within the same column show significant differences between L-Phe applications by Duncan test $(p \leq 0.05)$. 


\begin{tabular}{|c|c|c|c|c|c|}
\hline \multirow[t]{2}{*}{ Phenolics } & \multirow[t]{2}{*}{ Applications } & \multicolumn{4}{|c|}{ Culture duration (days) } \\
\hline & & $1 \mathrm{st}$ & 3rd & 7th & Mean \\
\hline \multirow[t]{5}{*}{$\begin{array}{l}\text { p-coumaric acid (mg } 100 \\
\mathrm{ml}^{-1} \text { ) }\end{array}$} & Control & $\begin{array}{l}3.94 \pm 0.19 \\
\mathrm{Ab}\end{array}$ & $\begin{array}{l}2.11 \pm 0.29 \\
\mathrm{BC}\end{array}$ & $\begin{array}{l}0.23 \pm 0.01 \\
\mathrm{Ca}\end{array}$ & 2.09 \\
\hline & $\begin{array}{l}0.25 \mathrm{mM} \mathrm{L}- \\
\text { Phe }\end{array}$ & $\begin{array}{l}0.18 \pm 0.00 \\
\mathrm{BC}\end{array}$ & $\begin{array}{l}1.06 \pm 0.17 \\
\text { Ac }\end{array}$ & $\begin{array}{l}0.00 \pm 0.00 \\
\mathrm{Cb}\end{array}$ & 0.41 \\
\hline & $\begin{array}{l}0.50 \mathrm{mM} \mathrm{L-} \\
\text { Phe }\end{array}$ & $\begin{array}{l}2.19 \pm 0.12 \\
\mathrm{Bb}\end{array}$ & $\begin{array}{l}4.44 \pm 0.20 \\
A b\end{array}$ & $\begin{array}{l}0.00 \pm 0.00 \\
\mathrm{Cb}\end{array}$ & 2.21 \\
\hline & $\begin{array}{l}1.00 \mathrm{mM} \mathrm{L-} \\
\text { Phe }\end{array}$ & $\begin{array}{l}15.83 \pm \\
0.76 \mathrm{Aa}\end{array}$ & $\begin{array}{l}10.07 \pm 0.75 \\
\mathrm{Ba}\end{array}$ & $\begin{array}{l}1.92 \pm 1.92 \\
\mathrm{Ca}\end{array}$ & 9.28 \\
\hline & Mean & 5.53 & 4.42 & 0.54 & \\
\hline \multirow[t]{5}{*}{$\begin{array}{l}\text { Caffeic acid ( } \mu \mathrm{g} 100 \mathrm{ml}^{-} \\
\left.{ }^{1}\right)\end{array}$} & Control & $\begin{array}{l}0.01 \pm 0.00 \\
\text { Ac }\end{array}$ & $\begin{array}{l}0.00 \pm 0.00 \\
\mathrm{Bb}\end{array}$ & $\begin{array}{l}0.00 \pm 0.00 \\
\mathrm{Ba}\end{array}$ & 0.005 \\
\hline & $\begin{array}{l}0.25 \mathrm{mM} \mathrm{L-} \\
\text { Phe }\end{array}$ & $\begin{array}{l}2.25 \pm 0.11 \\
\mathrm{Aa}\end{array}$ & $\begin{array}{l}0.00 \pm 0.00 \\
\mathrm{Bb}\end{array}$ & $\begin{array}{l}0.00 \pm 0.00 \\
\mathrm{Ba}\end{array}$ & 0.75 \\
\hline & $\begin{array}{l}0.50 \mathrm{mM} \mathrm{L}- \\
\text { Phe }\end{array}$ & $\begin{array}{l}0.88 \pm 0.03 \\
A b\end{array}$ & $\begin{array}{l}0.00 \pm 0.00 \\
\mathrm{Bb}\end{array}$ & $\begin{array}{l}0.00 \pm 0.00 \\
\mathrm{Ba}\end{array}$ & 0.29 \\
\hline & $\begin{array}{l}1.00 \mathrm{mM} \mathrm{L-} \\
\text { Phe }\end{array}$ & $\begin{array}{l}0.71 \pm 0.18 \\
A b\end{array}$ & $\begin{array}{l}0.87 \pm 0.02 \\
\mathrm{Aa}\end{array}$ & $\begin{array}{l}0.00 \pm 0.00 \\
\mathrm{Ba}\end{array}$ & 0.53 \\
\hline & Mean & 0.96 & 0.22 & 0.00 & \\
\hline \multirow[t]{5}{*}{$\begin{array}{l}\text { Ferulic acid ( } \mu \mathrm{g} 100 \mathrm{ml}^{-} \\
\text {1) }\end{array}$} & Control & $\begin{array}{l}0.00 \pm 0.00 \\
\mathrm{Ac}\end{array}$ & $\begin{array}{l}0.00 \pm 0.00 \\
A b\end{array}$ & $\begin{array}{l}0.00 \pm 0.00 \\
\mathrm{Aa}\end{array}$ & 0.00 \\
\hline & $\begin{array}{l}0.25 \mathrm{mM} \mathrm{L}- \\
\text { Phe }\end{array}$ & $\begin{array}{l}0.00 \pm 0.00 \\
B C\end{array}$ & $\begin{array}{l}0.29 \pm 0.05 \\
A b\end{array}$ & $\begin{array}{l}0.00 \pm 0.00 \\
\mathrm{Ba}\end{array}$ & 0.10 \\
\hline & $\begin{array}{l}0.50 \mathrm{mM} \mathrm{L-} \\
\text { Phe }\end{array}$ & $\begin{array}{l}0.43 \pm 0.01 \\
A b\end{array}$ & $\begin{array}{l}0.00 \pm 0.00 \\
\mathrm{Bb}\end{array}$ & $\begin{array}{l}0.00 \pm 0.00 \\
\mathrm{Ba}\end{array}$ & 0.14 \\
\hline & $\begin{array}{l}1.00 \mathrm{mM} \mathrm{L-} \\
\text { Phe }\end{array}$ & $\begin{array}{l}3.58 \pm 0.04 \\
\mathrm{Aa}\end{array}$ & $\begin{array}{l}2.76 \pm 0.45 \\
\mathrm{Aa}\end{array}$ & $\begin{array}{l}0.00 \pm 0.00 \\
\mathrm{Ba}\end{array}$ & 2.11 \\
\hline & Mean & 1.00 & 0.76 & 0.00 & \\
\hline \multirow[t]{2}{*}{$\begin{array}{l}\text { Chlorogenic acid ( } \mu \mathrm{g} 100 \\
\mathrm{ml}^{-1} \text { ) }\end{array}$} & Control & $\begin{array}{l}17.76 \pm 1.16 \\
\text { Cd }\end{array}$ & $\begin{array}{l}107.77 \pm 3.05 \\
\text { Ac }\end{array}$ & $\begin{array}{l}37.85 \pm 1.34 \\
\mathrm{Bd}\end{array}$ & 54.46 \\
\hline & $\begin{array}{l}0.25 \mathrm{mM} \mathrm{L}- \\
\text { Phe }\end{array}$ & $\begin{array}{l}40.71 \pm 0.88 \\
\mathrm{Cb}\end{array}$ & $\begin{array}{l}158.85 \pm 3.23 \\
A b\end{array}$ & $\begin{array}{l}94.77 \pm 1.32 \\
\mathrm{Bb}\end{array}$ & 98.11 \\
\hline
\end{tabular}

* Different capital letters within the same row show significant differences between culture durations by Duncan test $(p \leq 0.05)$. Different small letters within the same column show significant differences between L-Phe applications by Duncan test $(p \leq 0.05)$. 


\begin{tabular}{|c|c|c|c|c|c|}
\hline \multirow[t]{2}{*}{ Phenolics } & \multirow[t]{2}{*}{ Applications } & \multicolumn{4}{|c|}{ Culture duration (days) } \\
\hline & & $1 \mathrm{st}$ & 3rd & 7th & Mean \\
\hline & $\begin{array}{l}0.50 \mathrm{mM} \mathrm{L}- \\
\text { Phe }\end{array}$ & $\begin{array}{l}34.24 \pm 1.36 \\
\text { Cc }\end{array}$ & $\begin{array}{l}189.36 \pm 3.63 \\
\mathrm{Aa}\end{array}$ & $\begin{array}{l}73.22 \pm 5.37 \\
\mathrm{BC}\end{array}$ & 98.94 \\
\hline & $\begin{array}{l}1.00 \mathrm{mM} \mathrm{L-} \\
\text { Phe }\end{array}$ & $\begin{array}{l}80.46 \pm 1.20 \\
\mathrm{Ca}\end{array}$ & $\begin{array}{l}200.41 \pm 5.10 \\
\mathrm{Aa}\end{array}$ & $\begin{array}{l}173.76 \pm 3.08 \\
\mathrm{Ba}\end{array}$ & 151.55 \\
\hline & Mean & 43.29 & 164.10 & 94.90 & \\
\hline
\end{tabular}

* Different capital letters within the same row show significant differences between culture durations by Duncan test $(p \leq 0.05)$. Different small letters within the same column show significant differences between L-Phe applications by Duncan test $(p \leq 0.05)$.

The amounts of phenolic contents per flask obtained by collecting the phenolics accumulated in roots and leaked into the culture medium were presented in Table 3. When TPC per flask was examined, the greatest amount ( $3.39 \mathrm{mg} \mathrm{flask}^{-1}$ ) was obtained from the flask applied with $0.5 \mathrm{mM} \mathrm{L}$-Phe and harvested on the 3rd day of culture. Of the phenolics, the amounts of gallic acid, catechin, epicatechin and vanillin obtained per flask reached the greatest levels with $0.5 \mathrm{mM}$ L-Phe application for 3 days. The greatest cinnamic acid $\left(10.42 \mu\right.$ flask $\left.^{-1}\right)$, p-coumaric acid $\left(10.80 \mathrm{mg} \mathrm{flask}^{-1}\right)$ and ferulic acid (1.63-1.98 $\mu \mathrm{g}$ flask $^{-1}$ ) were found in the cultures with $1.00 \mathrm{mM} \mathrm{L-Phe} \mathrm{application} \mathrm{for} 1$ day while maximum rosmarinic acid $\left(10.90 \mu \mathrm{g} \mathrm{flask}^{-1}\right)$, and chlorogenic acid $\left(704.94 \mu \mathrm{g} \mathrm{flask}^{-1}\right)$ obtained from the flasks applied with $1.00 \mathrm{mM}$ L-Phe for 3 days. Caffeic acid was found to reach the greatest value with $0.25 \mathrm{mM}$ L-Phe application for 1 day. 
Table 3

Effects of L-Phenylalanine (L-Phe) application and culture duration on the phenolics per flask (Rutin, ocoumaric acid and quercetin could not be detected)

\begin{tabular}{|c|c|c|c|c|c|}
\hline \multirow[t]{2}{*}{ Phenolics } & \multirow[t]{2}{*}{ Applications } & \multicolumn{4}{|c|}{ Culture duration (days) } \\
\hline & & $1 \mathrm{st}$ & 3rd & 7th & Mean \\
\hline \multirow{5}{*}{$\begin{array}{l}\text { Total phenolic } \\
\text { contents } \\
\left(\mathrm{mg} \mathrm{flask}^{-1}\right)\end{array}$} & Control & $1.73 \pm 0.07 \mathrm{Cc}^{*}$ & $2.42 \pm 0.08 \mathrm{Ac}$ & $2.11 \pm 0.04 \mathrm{Bc}$ & 2.09 \\
\hline & $\begin{array}{l}0.25 \mathrm{mM} \mathrm{L-} \\
\text { Phe }\end{array}$ & $2.49 \pm 0.08 \mathrm{ABb}$ & $2.82 \pm 0.09 \mathrm{Ab}$ & $2.43 \pm 0.05 \mathrm{Bb}$ & 2.58 \\
\hline & $\begin{array}{l}0.50 \mathrm{mM} \mathrm{L-} \\
\text { Phe }\end{array}$ & $2.73 \pm 0.06 \mathrm{Bab}$ & $3.39 \pm 0.08 \mathrm{Aa}$ & $3.15 \pm 0.05 \mathrm{Aa}$ & 3.09 \\
\hline & $\begin{array}{l}1.00 \mathrm{mM} \mathrm{L-} \\
\text { Phe }\end{array}$ & $2.83 \pm 0.08 \mathrm{Ba}$ & $3.18 \pm 0.08 \mathrm{Aab}$ & $3.04 \pm 0.05 \mathrm{Aba}$ & 3.02 \\
\hline & Mean & 2.45 & 2.95 & 2.68 & \\
\hline \multirow{5}{*}{$\begin{array}{l}\text { Gallic acid } \\
\left(\mu \mathrm{g} \text { flask }^{-1}\right)\end{array}$} & Control & $5.89 \pm 0.25 \mathrm{Bd}$ & $7.32 \pm 0.06 \mathrm{Ad}$ & $8.04 \pm 0.34 \mathrm{Ad}$ & 7.08 \\
\hline & $\begin{array}{l}0.25 \mathrm{mM} \mathrm{L-} \\
\text { Phe }\end{array}$ & $11.92 \pm 0.39 \mathrm{Bc}$ & $12.22 \pm 0.58 \mathrm{Bc}$ & $15.21 \pm 0.27 \mathrm{Ab}$ & 13.12 \\
\hline & $\begin{array}{l}0.50 \mathrm{mM} \mathrm{L-} \\
\text { Phe }\end{array}$ & $\begin{array}{l}26.64 \pm 0.70 \\
\text { ABa }\end{array}$ & $28.58 \pm 0.55 \mathrm{Aa}$ & $24.53 \pm 0.15 \mathrm{Ba}$ & 26.59 \\
\hline & $\begin{array}{l}1.00 \mathrm{mM} \mathrm{L-} \\
\text { Phe }\end{array}$ & $15.52 \pm 0.41 \mathrm{Ab}$ & $\begin{array}{l}15.10 \pm 0.18 \\
\mathrm{ABb}\end{array}$ & $14.12 \pm 0.13 \mathrm{Bc}$ & 14.91 \\
\hline & Mean & 15.00 & 15.81 & 15.48 & \\
\hline \multirow{5}{*}{$\begin{array}{l}\text { Catechin } \\
\left(\mu \mathrm{g} \text { flask }^{-1}\right)\end{array}$} & Control & $69.72 \pm 2.87 \mathrm{Bc}$ & $107.85 \pm 4.24 \mathrm{Ad}$ & $95.83 \pm 1.02 \mathrm{Ac}$ & 91.13 \\
\hline & $\begin{array}{l}0.25 \mathrm{mM} \mathrm{L-} \\
\text { Phe }\end{array}$ & $\begin{array}{l}278.40 \pm 4.34 \\
\mathrm{Aa}\end{array}$ & $202.55 \pm 15.3 \mathrm{Bc}$ & $\begin{array}{l}116.38 \pm 4.16 \\
\mathrm{Cb}\end{array}$ & 199.11 \\
\hline & $\begin{array}{l}0.50 \mathrm{mM} \mathrm{L-} \\
\text { Phe }\end{array}$ & $\begin{array}{l}220.64 \pm 11.5 \\
\mathrm{Bb}\end{array}$ & $368.70 \pm 18.1 \mathrm{Aa}$ & $\begin{array}{l}326.79 \pm 3.39 \\
\text { Аа }\end{array}$ & 305.37 \\
\hline & $\begin{array}{l}1.00 \mathrm{mM} \mathrm{L-} \\
\text { Phe }\end{array}$ & $\begin{array}{l}303.55 \pm 6.96 \\
\mathrm{Aa}\end{array}$ & $264.39 \pm 4.35 \mathrm{Bb}$ & $90.48 \pm 2.18 \mathrm{Cc}$ & 219.47 \\
\hline & Mean & 218.08 & 235.87 & 157.37 & \\
\hline \multirow{3}{*}{$\begin{array}{l}\text { Epicatechin } \\
\left(\mu \text { flask }^{-1}\right)\end{array}$} & Control & $7.70 \pm 0.27 \mathrm{Cd}$ & $12.84 \pm 0.07 \mathrm{Bd}$ & $15.36 \pm 0.69 \mathrm{Ab}$ & 11.97 \\
\hline & $\begin{array}{l}0.25 \mathrm{mM} \mathrm{L}- \\
\text { Phe }\end{array}$ & $11.00 \pm 0.28 \mathrm{Bc}$ & $16.29 \pm 0.79 \mathrm{Ac}$ & $14.60 \pm 0.31 \mathrm{Ab}$ & 13.96 \\
\hline & $\begin{array}{l}0.50 \mathrm{mM} \mathrm{L}- \\
\text { Phe }\end{array}$ & $29.62 \pm 0.65 \mathrm{Ba}$ & $42.03 \pm 0.77 \mathrm{Aa}$ & $39.61 \pm 0.10 \mathrm{Aa}$ & 37.09 \\
\hline
\end{tabular}

* Different capital letters within the same row show significant differences between culture durations by Duncan test $(p \leq 0.05)$. Different small letters within the same column show significant differences between L-Phe applications by Duncan test $(p \leq 0.05)$. 


\begin{tabular}{|c|c|c|c|c|c|}
\hline & $\begin{array}{l}1.00 \mathrm{mM} \mathrm{L}- \\
\text { Phe }\end{array}$ & $24.70 \pm 0.58 \mathrm{Ab}$ & $25.40 \pm 0.13 \mathrm{Ab}$ & $18.65 \pm 6.60 \mathrm{Ab}$ & 22.91 \\
\hline & Mean & 18.25 & 24.14 & 22.05 & \\
\hline \multirow{5}{*}{$\begin{array}{l}\text { Vanillin } \\
\left(\mu \mathrm{g} \text { flask }^{-1}\right)\end{array}$} & Control & $3.98 \pm 0.04 \mathrm{Bc}$ & $4.50 \pm 0.31 \mathrm{ABC}$ & $4.86 \pm 0.07 \mathrm{Ac}$ & 4.45 \\
\hline & $\begin{array}{l}0.25 \mathrm{mM} \mathrm{L-} \\
\text { Phe }\end{array}$ & $6.71 \pm 0.28 \mathrm{Bb}$ & $8.54 \pm 0.28 \mathrm{Ab}$ & $8.77 \pm 0.09 \mathrm{Ab}$ & 8.01 \\
\hline & $\begin{array}{l}0.50 \mathrm{mM} \mathrm{L}- \\
\text { Phe }\end{array}$ & $10.44 \pm 0.02 \mathrm{Ca}$ & $14.80 \pm 0.23 \mathrm{Aa}$ & $11.97 \pm 0.15 \mathrm{Ba}$ & 12.40 \\
\hline & $\begin{array}{l}1.00 \mathrm{mM} \mathrm{L-} \\
\text { Phe }\end{array}$ & $6.65 \pm 0.53 \mathrm{Ab}$ & $6.64 \pm 1.06 \mathrm{Abc}$ & $5.75 \pm 0.64 \mathrm{Ac}$ & 6.35 \\
\hline & Mean & 6.94 & 8.62 & 7.84 & \\
\hline \multirow{5}{*}{$\begin{array}{l}\text { Cinnamic acid } \\
\left(\mu \mathrm{g} \mathrm{flask}{ }^{-1}\right)\end{array}$} & Control & $1.08 \pm 0.19 \mathrm{Ac}$ & $1.41 \pm 0.06 \mathrm{Ad}$ & $1.30 \pm 0.02 \mathrm{Ac}$ & 1.27 \\
\hline & $\begin{array}{l}0.25 \mathrm{mM} \mathrm{L}- \\
\text { Phe }\end{array}$ & $1.95 \pm 0.14 \mathrm{Bc}$ & $3.79 \pm 0.16 \mathrm{Ac}$ & $3.70 \pm 0.18 \mathrm{Ab}$ & 3.15 \\
\hline & $\begin{array}{l}0.50 \mathrm{mM} \mathrm{L-} \\
\text { Phe }\end{array}$ & $4.16 \pm 0.18 \mathrm{Bb}$ & $5.30 \pm 0.10 \mathrm{Ab}$ & $4.81 \pm 0.25 \mathrm{ABa}$ & 4.76 \\
\hline & $\begin{array}{l}1.00 \mathrm{mM} \mathrm{L-} \\
\text { Phe }\end{array}$ & $10.42 \pm 0.32 \mathrm{Aa}$ & $7.08 \pm 0.26 \mathrm{Ba}$ & $4.33 \pm 0.23 \mathrm{Cab}$ & 7.28 \\
\hline & Mean & 4.40 & 4.40 & 3.54 & \\
\hline \multirow{5}{*}{$\begin{array}{l}\text { Rosmarinic } \\
\text { acid } \\
\left(\mu \text { flask }^{-1}\right)\end{array}$} & Control & $4.85 \pm 0.11 \mathrm{Bc}$ & $6.07 \pm 0.12 \mathrm{Ab}$ & $4.19 \pm 0.04 \mathrm{Cc}$ & 5.03 \\
\hline & $\begin{array}{l}0.25 \mathrm{mM} \mathrm{L-} \\
\text { Phe }\end{array}$ & $7.35 \pm 0.27 \mathrm{Ab}$ & $9.33 \pm 0.88 \mathrm{Aa}$ & $8.47 \pm 0.11 \mathrm{Ab}$ & 8.38 \\
\hline & $\begin{array}{l}0.50 \mathrm{mM} \mathrm{L-} \\
\text { Phe }\end{array}$ & $9.88 \pm 0.32 \mathrm{Aa}$ & $8.61 \pm 0.49 \mathrm{Aa}$ & $10.03 \pm 0.38 \mathrm{Aa}$ & 9.51 \\
\hline & $\begin{array}{l}1.00 \mathrm{mM} \mathrm{L-} \\
\text { Phe }\end{array}$ & $10.07 \pm 0.09 \mathrm{Ba}$ & $10.90 \pm 0.13 \mathrm{Aa}$ & $9.76 \pm 0.16 \mathrm{Ba}$ & 10.24 \\
\hline & Mean & 8.04 & 8.73 & 8.11 & \\
\hline \multirow{2}{*}{$\begin{array}{l}\text { p-coumaric } \\
\text { acid } \\
\left(\mathrm{mg} \mathrm{flask}{ }^{-1}\right)\end{array}$} & Control & $2.14 \pm 0.08 \mathrm{Ac}$ & $1.81 \pm 0.36 \mathrm{Ac}$ & $0.07 \pm 0.00 \mathrm{Bb}$ & 1.34 \\
\hline & $\begin{array}{l}0.25 \mathrm{mM} \mathrm{L-} \\
\text { Phe }\end{array}$ & $4.80 \pm 0.07 \mathrm{Ab}$ & $1.72 \pm 0.20 \mathrm{Bc}$ & $0.00 \pm 0.00 \mathrm{Cb}$ & 2.14 \\
\hline
\end{tabular}

* Different capital letters within the same row show significant differences between culture durations by Duncan test $(p \leq 0.05)$. Different small letters within the same column show significant differences between L-Phe applications by Duncan test $(p \leq 0.05)$. 


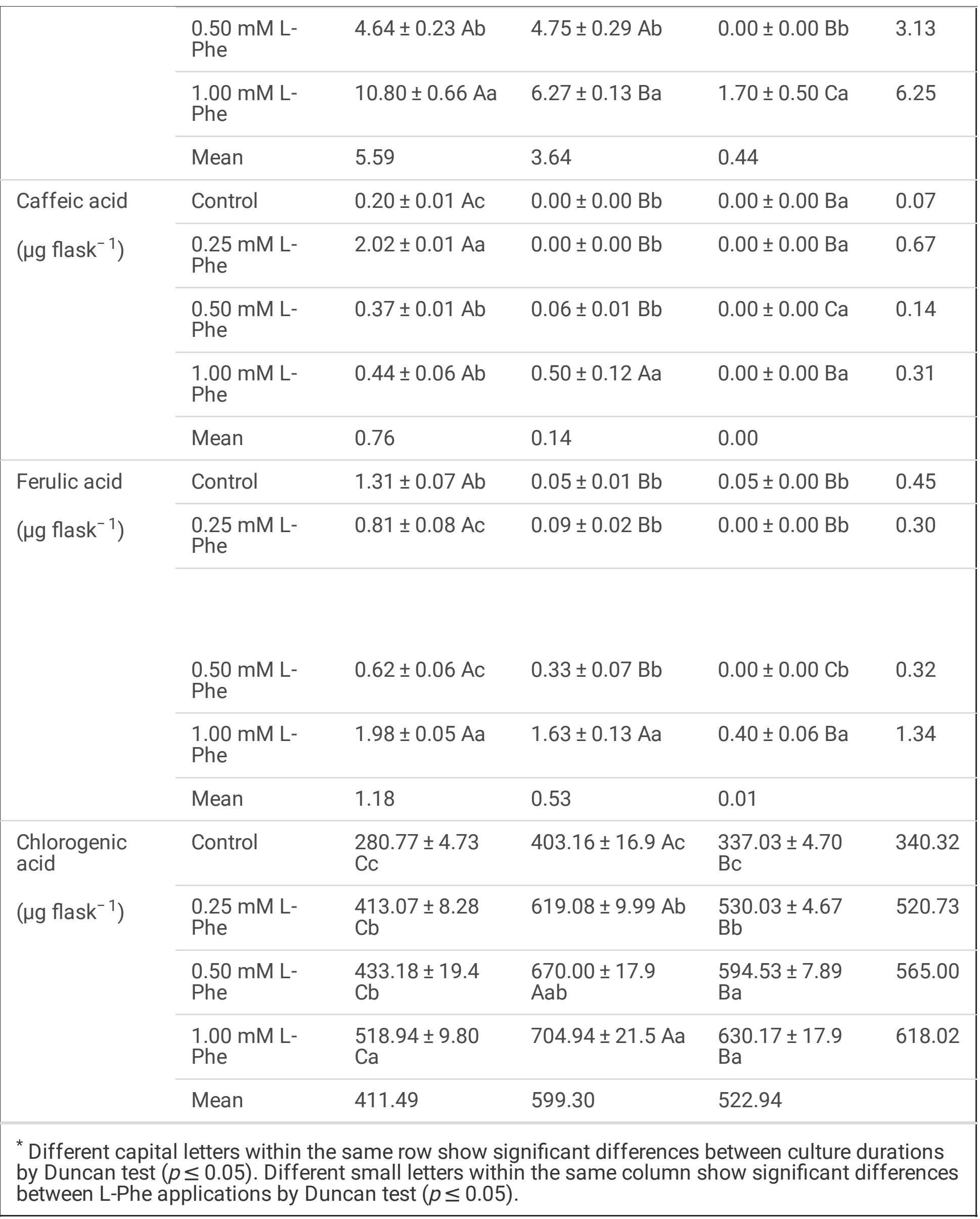




\section{Effects of L-Phe applications and culture duration on the PAL activity}

PAL enzyme activity was another parameter studied in this study since it is an enzyme that takes part in the phenylpropanoid pathway in plants and the synthesis of many secondary metabolites by converting L-Phe to trans-cinnamic acid (Syklowska-Baranek et al. 2012). As a result of the analysis of variance in terms of PAL activity, the interaction of application*culture duration was found to be statistically significant $(p \leq 0.05)$. The highest PAL enzyme activity was found in roots harvested on the 1 st day in the control group with $3.45 \mu \mathrm{mol}$ trans-cinnamic acid g-1 fresh root h-1 (Fig. 5). But PAL activity showed a sharp decrease in control roots harvested on day 3 and 7 as 0.91 and $0.49 \mu$ mol trans-cinnamic acid g- 1 fresh root h-1, respectively. A similar pattern was observed with $0.5 \mathrm{mM}$ L-Phe application. One of the most striking results was obtained with $0.25 \mathrm{mM} \mathrm{L-Phe} \mathrm{application.} \mathrm{PAL} \mathrm{activity,} \mathrm{which} \mathrm{was} \mathrm{high} \mathrm{on} \mathrm{the}$ 3rd day in this application, fell rapidly on the 7th day and decreased about 10 times. According to these results, it was determined that there was no relationship between PAL activity and the amount of tropane alkaloids.

\section{Discussion}

In this study, the effects of $0.25,0.50$, and $1.00 \mathrm{mM} \mathrm{L-Phe} \mathrm{applied} \mathrm{to} \mathrm{adventitious} \mathrm{root} \mathrm{cultures} \mathrm{of} \mathrm{H}$. niger on root growth and production of scopolamine, hyoscyamine and phenolics in roots and culture medium were investigated at different culture durations. Biotic and abiotic elicitors applied to cultures under in vitro conditions can increase the production of metabolites by stimulating the biosynthesis steps of secondary metabolites (Shakeran et al. 2015). Another approach to increase the in vitro secondary metabolite production is precursor addition to the culture medium. Increasing in vitro secondary metabolite production with precursor applications is a promising approach and is used in the production of many pharmaceutically effective secondary metabolites (Namdeo et al. 2007). However, success in precursor applications can vary significantly depending on the precursor, its concentrations, culture condition, application time, the targeted biosynthetic pathway and metabolite (Jackson and Attalla 2010). The syntheses of the metabolites reach the greatest levels in a certain period of the culture, and metabolite accumulation in cultures harvested before or after this period could significantly reduce (Lee et al. 2001; Moussous et al. 2018; Ono et al. 1998). Therefore, in this study, L-Phe applications as a precursor and different culture durations were used to determine their effects on root growth, alkaloid and phenolic production in $\mathrm{H}$. niger adventitious root cultures and to create a protocol that provides high metabolite yield.

When the effects of L-Phe and culture durations on root fresh weight, growth index and root dry weight were assessed, important differences were found. Root growth parameters increased in parallel with increasing L-Phe concentration and culture duration. Stimulating effects of L-Phe on cell and root growth have been shown in Arnebia euchroma cell cultures (Syklowska-Baranek et al. 2012) and Echinacea purpurea adventitious root cultures (Mobin et al. 2015). The findings that L-Phe applications increase 
biomass in different plants such as Datura stramonium (Moursy et al. 1988), Hydrocotyle bonariensis (Masoumian et al. 2011), Origanum majorana (Korkor et al. 2017) and Ocimum basilicum (Koca and Karaman 2015) support our study. The growth-promoting effect of L-Phe in plant cells is thought to be due to its positive effects on the gibberellin biosynthesis mechanism and the accumulation of amino acids (Musbah and Ibrahim 2019). On the other hand, high L-Phe concentrations inhibited cell growth (Edahiro et al. 2005) and even reduced fresh and dry cell weight (Palacio et al. 2011). Coruzzi and Last (2000) found that increasing L-Phe concentration increases the dissolved nitrogen in cells and increases the osmotic pressure, as a result, the cell wall that draws water from neighbouring cells becomes softer and thinner and can easily be broken down. Thus, it causes a decrease in the amount of biomass depending on the increase in L-Phe concentration. Demirci et al. (2020) found that L-Phe applications in Echinacea purpurea hairy roots did not have a significant effect on root growth, but fresh and dry root weights and growth index increased in parallel to the culture duration prolonged. As a result, the effect of L-Phe applications on biomass yield varies significantly depending on the L-Phe concentration and culture duration (Demirci et al. 2020; Masoumian et al. 2011; Palacio et al. 2011).

The changes in amounts of hyoscyamine and scopolamine were also examined according to the L-Phe applications and culture duration. The use of L-Phe in appropriate concentrations increased the alkaloid accumulation. Similarly, in the previous studies (Hashimoto and Yamada 1987; Hassan and Jassim 2018) showed that L-Phe application as a precursor significantly increased the accumulation of in vitro alkaloid production. Khanna et al. (2005) stated that the effect of L-Phe promoting alkaloid production is due to the role of L-Phe as a signal molecule in the expression of enzymes that catalyse the synthesis of alkaloids. It is known that L-Phe applications at the optimum concentrations can be used as an effective method for secondary metabolite production. However, high doses of L-Phe administration decreased metabolite production (Demirci et al. 2020, 2021). The precursor used in high doses can reduce the amount of metabolites by causing feedback inhibition in the secondary metabolite biosynthesis pathway (Ouyang et al. 2005). Therefore, determining the most appropriate concentration is of great importance in precursor applications. In this study, the amounts of scopolamine and hyoscyamine in roots, in the culture medium changed depending on the L-Phe concentration and the culture duration. Previous studies on different plants have also obtained results that support our findings (Boitel-Conti et al. 2000; Hassan and Jassim 2018; Masoumian et al. 2011).

Another important factor affecting in vitro secondary metabolite production is culture duration. In this study, the greatest alkaloid production was obtained from the cultures harvested on the 3rd day, and the amount of alkaloid decreased on the 7th day. Similarly, Lee et al. (2001) reported that secondary metabolite yield decreased with the increasing duration of in vitro cultures. Figuero et al. (2010) reported that hypericin decreased similarly in Hypericum perforatum, and the reason for this decrease was that the plant's energy was used for growth rather than producing secondary metabolites with the prolongation of the culture duration. The selection of the most appropriate culture duration may vary significantly depending on the genotype, applications, and the targeted secondary metabolites. The accumulation of different alkaloids following biotic and abiotic elicitor applications in different plants vary significantly according to the culture duration (Moharrami et al. 2017). Therefore, it is possible to increase metabolite 
productivity by determining the most appropriate culture duration when synthesis is at the highest level for in vitro secondary metabolite production (Moussous et al. 2018). Secondary metabolite yield will be low if in vitro plants are not harvested during the period when secondary metabolite production is high. It is thought that the decrease in secondary metabolite yield with prolonged culture duration is caused by the biotransformation of secondary metabolites or the decomposition of applied elicitor and precursor materials over time and losing their effect (Ono et al. 1998).

In addition to tropane alkaloids, H. niger has many valuable phenolics (Jassbi et al. 2014). However, as a result of the literature reviews, there is no research on the production of phenolics in $H$. niger cultures. As a result of this study, phenolic contents were significantly changed according to the L-Phe concentrations and culture durations. Phenolics are synthesized from L-Phe and L-tyrosine via shikimic acid biosynthesis. Especially, L-Phe is the most important amino acid in this biosynthesis pathway and is the common precursor of most phenolics (Heleno et al. 2015). It is known that the amount of phenolics increases significantly with L-Phe application in different plants in vitro cultures (Mobin et al. 2015, Demirci et al. 2021, Koca and Karaman et al. 2015, Palacio et al. 2011). However, the L-Phe concentration is important. Reductions in the amount of phenolic substance have been reported with high concentration L-Phe (Demirci et al. 2020, Mobin et al. 2015).

According to the results, it may be possible to produce high amounts of phenolics by appropriate L-Phe application and culture duration. After L-Phe application, the greatest amounts of phenolics were detected in the roots harvested on the 1st and 3rd days of the culture, while it was observed that the amount of phenolics in the cultures decreased with the extension of the culture duration to 7 days. These results show that the culture duration is one of the most important criteria for secondary metabolite production and is in agreement with the results of previous studies performed on different plants (Demirci et al. 2020; 2021). It is stated that this stimulating effect of L-Phe in the production of phenolics is achieved by stimulating the enzymatic pathways in plants (Koca and Karaman 2015). Another reason for the decrease in secondary metabolite accumulation during the culture is that the elicitors or precursors used to increase the synthesis are broken down or depleted over time. Edahiro et al. (2005) stated that the decrease in L-Phe added to culture medium over time affects metabolite yield negatively.

The use of L-Phe, which acts as a precursor in the production of phenolics, is known to stimulate the expression of genes responsible for the PAL (Kikowska et al. 2012). PAL activity and phenolics amounts parallelly increased with methyl jasmonate, epibrassinolide, chitosan and L-Phe applications in previous studies (Koca and Karaman 2015, Kim et al. 2005). In this study, while PAL activity reached its highest level in cultures harvested on the 1st day except for $0.25 \mathrm{mM} \mathrm{L-Phe} \mathrm{application,} \mathrm{it} \mathrm{decreased} \mathrm{on} \mathrm{the} \mathrm{3rd}$ and 7th days. The greatest amounts of tropane alkaloids were obtained from the cultures applied with 0.5 $\mathrm{mM}$ L-Phe for 3 days in this study. Similarly, Kim et al. (2006a and b) reported that the induced PAL activity reached a maximum in 24 hours and that its maximum effect could continue for up to 48 hours. So it was seen that the effects of L-Phe applications on PAL activity were inconsistent. Kim et al. (2006a and $b$ ) also reported that there is no consistent relationship between amounts of PAL and TPC and an increase in phenolics could be due to other enzymes involved in the phenylpropanoid pathway. Similarly,

Page 22/31 
Li et al. (2007) showed in their study that the cinnamate 4-hydroxylase $\left(\mathrm{C}_{4} \mathrm{H}\right)$ significantly affects the formation of trans-cinnamic acid. On the other hand, contents of phenolic compounds were high in the 1st and 3rd days of cultures compared to the 7th day parallel to the PAL enzyme activity. In previous studies conducted with the idea that L-Phe, which is the precursor of trans-cinnamic acid, would increase PAL activity, it was reported that there was no statistically significant difference in PAL activity in plants treated with L-Phe (Koca 2013; Koca and Karaman 2015).

\section{Conclusion}

In this study, L-Phe applications and culture duration were examined on increasing the production of tropane alkaloids and phenolic compounds in adventitious root cultures of $\mathrm{H}$. niger, and it was found that L-Phe and culture duration significantly effective in increasing them when the appropriate L-Phe concentration and culture duration were selected. Based on the results, the greatest values in terms of root development were obtained in the $1 \mathrm{st}$ and 3 rd days after 0.50 and $1.00 \mathrm{mM}$ L-Phe applications. 0.50 $\mathrm{mM} \mathrm{L-Phe} \mathrm{and} \mathrm{3-day} \mathrm{culture} \mathrm{duration} \mathrm{were} \mathrm{determined} \mathrm{as} \mathrm{the} \mathrm{most} \mathrm{effective} \mathrm{combination} \mathrm{for}$ scopolamine and hyoscyamine alkaloids, as well as TPC, gallic acid, catechin, epicatechin, and vanillin. $1.00 \mathrm{mM}$ L-Phe for 1 day attracted attention as another combination that can be used in the production of phenolic compounds. The effects of L-Phe applications on PAL enzyme activity were inconsistent while PAL activity and phenolic compounds were similarly high on the 1 st and 3rd days of culture. Briefly, when appropriate L-Phe concentrations and culture duration are used, it is possible to increase the production of tropane alkaloids and phenolic compounds in $\mathrm{H}$. niger root cultures. To our best knowledge, this study is the first to examine the effects of L-Phe and culture duration on alkaloid and phenolic production from H. niger adventitious root cultures.

\section{Declarations}

Funding: This study was funded by the Scientific and Technological Research Council of Turkey (TUBITAK, TOVAG, 1002, Project No: 2180196).

Author Contributions TD: Conceptualization, Methodology, Formal analysis, Investigation, Writingoriginal draft, Writing-review \& editing, Supervision, Funding acquisition. IA: Formal analysis, Investigation. NGB: Writing-review \& editing, Supervision, Resources, Funding acquisition, Project administration.

\section{Compliance with ethical standards}

Conflicts of interest: The authors have no conflicts of interest to declare that are relevant to the content of this article.

Ethics approval: Not applicable

\section{References}


1. Al-Snafi AE (2018) Therapeutic importance of Hyoscyamus species grown in Iraq (Hyoscyamus albus, Hyoscyamus niger and Hyoscyamus reticulates)-A review. IOSR Journal of Pharmacy 8:18-32

2. Aljibouri AMJ, Al-samarraei KW, Abd AS, Mageed DM, Ali AJA (2012) Alkaloids production from callus of Hyoscyamus niger $\mathrm{L}$. in vitro. Journal of Life Sciences 6:874-882

3. Bedewitz MA, Góngora-Castillo E, Uebler JB, Gonzales-Vigil E, Wiegert-Rininger KE et al (2014) A rootexpressed L-phenylalanine: 4-hydroxyphenylpyruvate aminotransferase is required for tropane alkaloid biosynthesis in Atropa belladonna. Plant Cell 26:3745-3762

4. Boitel-Conti M, Laberche JC, Lanoue A, Ducrocq C, Sangwan-Norreel BS (2000) Influence of feeding precursors on tropane alkaloid production during an abiotic stress in Datura innoxia transformed roots. Plant Cell Tiss Org 60:131-137

5. Coruzzi GM, Last RL (2000) Amino acids in biochemistry and molecular biology of plants. American Society of Plant Phsiology Press, pp 358-410

6. D'Cunha GB, Satyanarayan V, Madhusudanan Nair P (1996) Purification of phenylalanine ammonia lyase from Rhodotorula glutinis. Phytochemistry 42:17-20

7. Dehghan E, Hakkinen ST, Oksman-Caldentey KM, Ahmadi FS (2012) Production of tropane alkaloids in diploid and tetraploid plants and in vitro hairy root cultures of Egyptian henbane (Hyoscyamus muticus L.). Plant Cell Tiss Org 110:35-44

8. Demirci T, Akcay UC, Baydar NG (2020) Effects of 24-epibrassinolide and I-phenylalanine on growth and caffeic acid derivative production in hairy root culture of Echinacea purpurea L. Moench. Acta Physiol Plant 42:id66

9. Demirci T, Asci OA, Baydar NG (2021) Influence of salicylic acid and L-phenylalanine on the accumulation of anthraquinone and phenolic compounds in adventitious root cultures of madder (Rubia tinctorum L.). Plant Cell Tiss Org 144:313-324

10. Dörnenburg H, Knorr D (1997) Challenges and opportunities for metabolite production from plant cell and tissue cultures. Food technology (Chicago) 51:47-54

11. Edahiro J, Nakamura M, Seki M, Furusaki S (2005) Enhanced accumulation of anthocyanin in cultured strawberry cells by repetitive feeding of L-phenylalanine into the medium. J Biosci Bioeng 99:43-47

12. Figueiró AA, Correa CM, Astarita LV, Santarém ER (2010) Long-term maintenance of in vitro cultures affects growth and secondary metabolism of St. John's Wort. Ciência Rural 40:2115-2121

13. Ghorbanpour M, Hatami M, Khavazi K (2013a) Role of plant growth promoting rhizobacteria on antioxidant enzyme activities and tropane alkaloid production of Hyoscyamus niger under water deficit stress. Turk J Biol 37:350-360

14. Ghorbanpour M, Omidi M, Etminan A, Hatami M, Shooshtari L (2013b) In vitro hyoscyamine and scopolamine production of black henbane (Hyoscyamus niger) from shoot tip culture under various plant growth regulators and culture media. Trakia Journal of Sciences 11:125-134

15. Hashimoto T, Yamada Y (1987) Effects of culture conditions on tropane alkaloid formation in Hyoscyamus niger suspension cultures. Agr Biol Chem Tokyo 51:2769-2774 
16. Hassan SA, Jassim EH (2018) Effect of L-phenylalanine on the production of some alkaloids and steroidal saponins of fenugreek cotyledons derived callus. Pak J Biotechnol 15:481-486

17. Heleno SA, Martins A, Queiroz MJ, Ferreira IC (2015) Bioactivity of phenolic acids: Metabolites versus parent compounds: A review. Food Chem 173:501-513

18. Hong MLK, Bhatt A, Ping NS, Keng CL (2012) Detection of elicitation effect on Hyoscyamus niger L. root cultures for the root growth and production of tropane alkaloids. Rom Biotech Lett 17:73407351

19. Jackson P, Attalla MI (2010) N-Nitrosopiperazines form at high pH in post-combustion capture solutions containing piperazine: a low-energy collisional behaviour study. Rapid Commun Mass Spectrom 24:3567-3577

20. Jassbi A, Miri R, Masroorbabanari M, Asadollahi M, Attarroshan M, Baldwin IT (2014) HPLC-DADESIMS analyses of Hyoscyamus niger and $H$. reticulatus for their antioxidant constituents. Austin Chromatography $1:$ id 1022

21. John H, Binder T, Hochstetter H, Thiermann H (2010) LC-ESI MS/MS quantification of atropine and six other antimuscarinic tropane alkaloids in plasma. Anal Bioanal Chem 396:751-763

22. Jones MPA, Saxena PK, Murch SJ (2009) Bioreactor production of Echinacea purpurea L. as a source of standardized, uniform plant material and a model system for studying plant secondary metabolism. Pharm Biol 47:25-25

23. Khanna R, Mathur AK, Mehrotra NK (2005) Selection of 3-fluorotyrosine tolerant callus lines in two cultivars of opium poppy (Papaver somniferum L.) and regeneration of plants through somatic embryogenesis. Curr Sci India 88:274-280

24. Kikowska M, Budzianowski J, Krawczyk A, Thiem B (2012) Accumulation of rosmarinic, chlorogenic and caffeic acids in in vitro cultures of Eryngium planum L. Acta Physiol Plant 34:2425-2433

25. Kim HJ, Chen F, Wang X, Choi JH (2006a) Effect of methyl jasmonate on phenolics, isothiocyanate, and metabolic enzymes in radish sprout (Raphanus sativus L.). J Agric Food Chem 54:7263-7269

26. Kim HJ, Chen F, Wang X, Rajapakse NC (2005) Effect of chitosan on the biological properties of sweet basil (Ocimum basilicum L.). J Agric Food Chem 53:3696-3701

27. Kim HJ, Chen F, Wang X, Rajapakse NC (2006b) Effect of methyl jasmonate on secondary metabolites of sweet basil (Ocimum basilicum L.). J Agric Food Chem 54:2327-2332

28. Koca N (2013) Ekzojen bitki büyüme düzenleyicilerinin ve fenilalaninin fesleğen (Ocimum basilicum L.) bitkisinde sekonder metabolitlere fenilalanin amonyum liyaz (PAL) enzim aktivitesine etkisi. Kahramanmaraş Sütçü İmam University

29. Koca N, Karaman S (2015) The effects of plant growth regulators and L-phenylalanine on phenolic compounds of sweet basil. Food Chem 166:515-521

30. Korkor AM, Mohamed SA, El-kafie OMA, Gohar AA (2017) Adaptation of the in vitro culture of Origanum majorana L. for production of phenolic acids. IOSR Journal of Pharmacy Biological Sciences 12:30-38 
31. Lee KT, Hirano H, Yamakawa T, Kodama T, Igarashi Y, Shimomura K (2001) Responses of transformed root culture of Atropa belladonna to salicylic acid stress. J Biosci Bioeng 91:586-589

32. Li P, Wu H, Geng S, Wang X, Lu W, Yang Y, Shultz LM, Tang T, Zhang N (2007) Germination and dormancy of seeds in Echinacea purpurea (L.) Moench (Asteraceae). Seed Sci Technol 35:9-20

33. Masoumian M, Arbakariya A, Syahida A, Maziah M (2011) Effect of precursors on flavonoid production by Hydrocotyle bonariensis callus tissues. Afr J Biotechnol 10:6021-6029

34. Mobin M, Wu CH, Tewari RK, Paek KY (2015) Studies on the glyphosate-induced amino acid starvation and addition of precursors on caffeic acid accumulation and profiles in adventitious roots of Echinacea purpurea (L.) Moench. Plant Cell Tiss Org 120:291-301

35. Moharrami F, Hosseini B, Sharafi A, Farjaminezhad M (2017) Enhanced production of hyoscyamine and scopolamine from genetically transformed root culture of Hyoscyamus reticulatus $\mathrm{L}$. elicited by iron oxide nanoparticles. In Vitro Cell Dev Biol Plant 53:104-111

36. Moursy HA, Hussein MS, El Bahr MK (1988) Effect of some alkaloid precursors on the growth and alkaloid production of Datura stramonium L. cultured in vitro. Egypt J Bot 31:153-165

37. Moussous A, Paris C, Khelifi-Slaoui M, Bekhouche M, Zaoui D, Rosloski SM, Makhzoum A, Desobry S, Khelifi $L$ (2018) Pseudomonas spp. increases root biomass and tropane alkaloid yields in transgenic hairy roots of Datura spp. In Vitro Cell Dev-PI 54:117-126

38. Murashige T, Skoog F (1962) A revised medium for rapid growth and bio assays with tobacco tissue cultures. Physiol Plantarum 15:473-497

39. Musbah HM, Ibrahim KM (2019) Effects of feeding tyrosine or phenylalanine on the accumulation of polyphenols in Coleus blumei in vivo and in vitro. Jornal of Biotechnology Research Center 13:35-43

40. Namdeo AG, Jadhav TS, Rai PK, Gavali S, Mahadik KR (2007) Precursor feeding for enhanced production of Secondary metabolites: A review. Pharmacogn Rev 1:227-231

41. Ono K, Nakao M, Toyota M, Terashi Y, Yamada M, Kohno T, Asakawa Y (1998) Catechin production in cultured Polygonum hydropiper cells Phytochemistry 49:1935-1939

42. Ouyang J, Wang XD, Zhao B, Wang YC (2005) Enhanced production of phenylethanoid glycosides by precursor feeding to cell culture of Cistanche deserticola. Process Biochem 40:3480-3484

43. Palacio L, Cantero JJ, Cusido R, Goleniowski M (2011) Phenolic compound production by Larrea divaricata Cav. plant cell cultures and effect of precursor feeding. Process Biochem 46:418-422

44. Pitta-Alvarez SI, Spollansky TC, Giulietti AM (2000) The influence of different biotic and abiotic elicitors on the production and profile of tropane alkaloids in hairy root cultures of Brugmansia candida. Enzyme Microb Technol 26:252-258

45. Shakeran Z, Keyhanfar M, Asghari G, Ghanadian M (2015) Improvement of atropine production by different biotic and abiotic elicitors in hairy root cultures of Datura metel. Turk J Biol 39:111-118

46. Singleton VL, Rossi JA (1965) Colorimetry of total phenolics with phosphomolybdic-phosphotungstic acid reagents. Am J Enol Vitic 16:144-158 
47. Syklowska-Baranek K, Pietrosiuk A, Naliwajski MR, Kawiak A, Jeziorek M, Wyderska S, Lojkowska E, Chinou I (2012) Effect of L-phenylalanine on PAL activity and production of naphthoquinone pigments in suspension cultures of Arnebia euchroma (Royle) Johnst. In Vitro Cellular \& Developmental Biology - Plant 48:555-564

48. Vuong TV, Franco C, Zhang W (2014) Treatment strategies for high resveratrol induction in Vitis vinifera L. cell suspension culture. Biotechnol Rep (Amst) 1-2:15-21

\section{Figures}
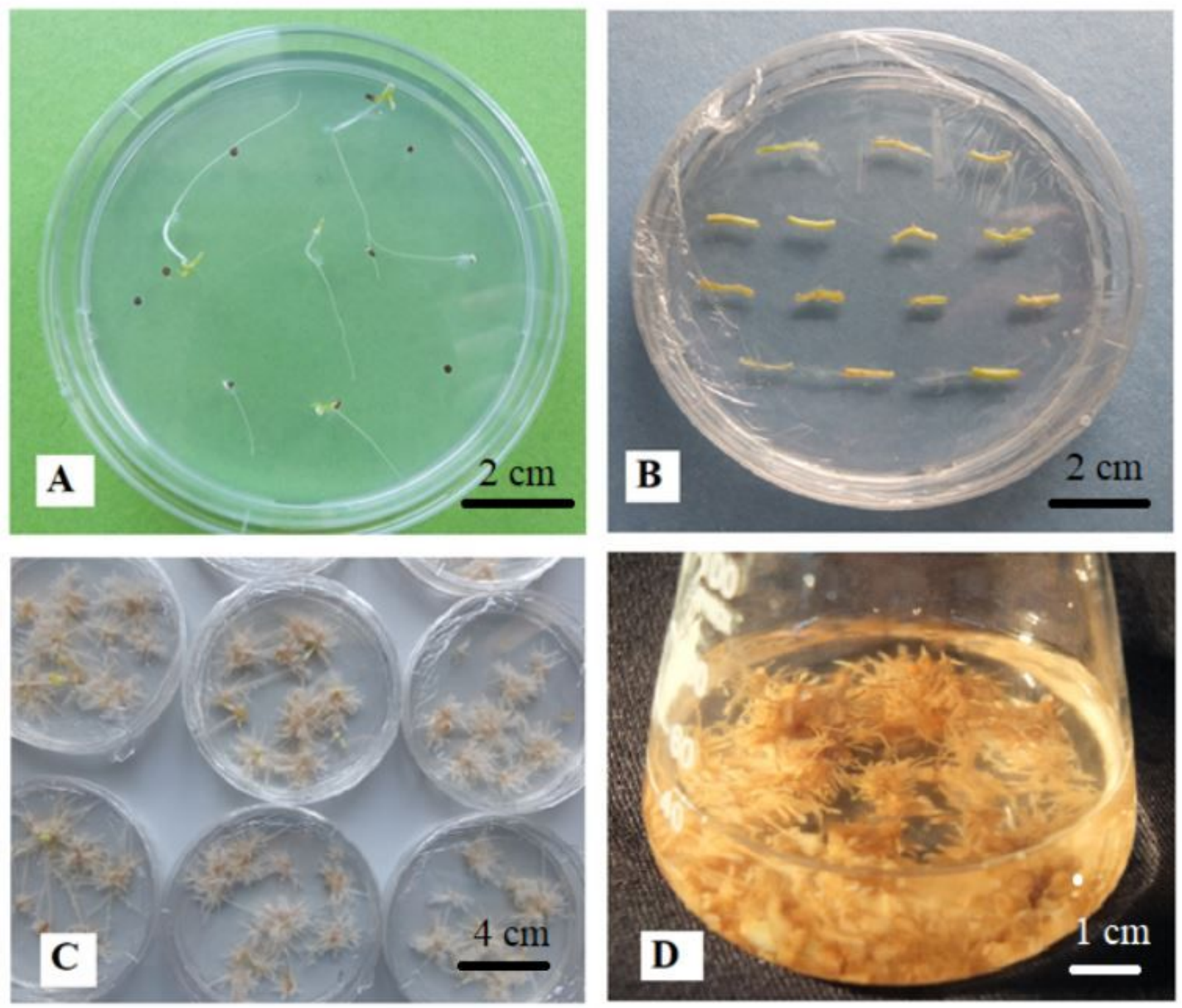

\section{Figure 1}

Obtaining adventitious root cultures in Hyoscyamus niger (A: germination of seeds, B: transferring explants to rooting medium, C: obtaining adventitious roots from explants, D: propagation of adventitious 
roots in liquid medium)
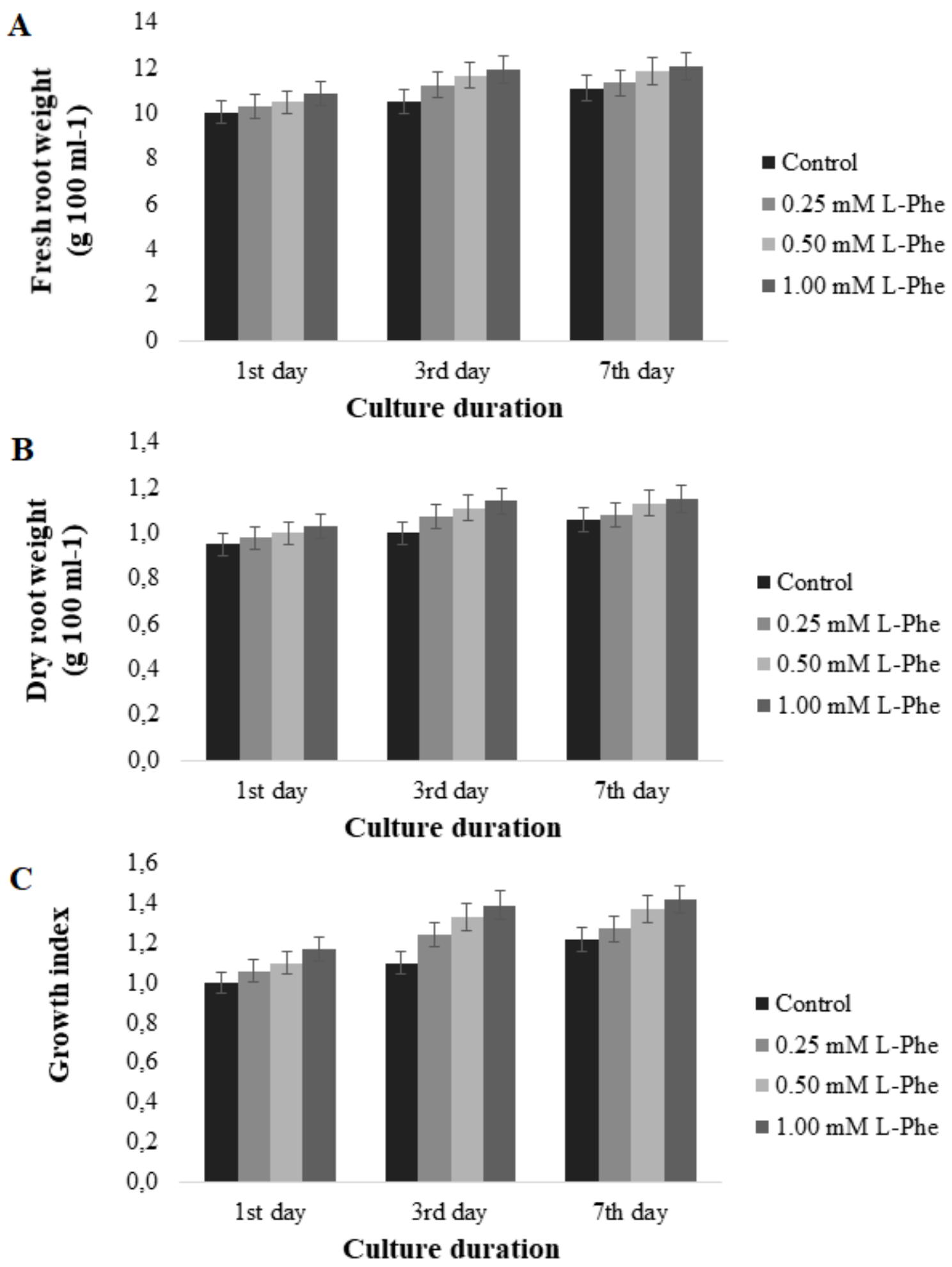

Figure 2

Effects of L-Phenylalanine (L-Phe) application and culture duration on growth parameter in adventitious roots of Hyoscyamus niger A: Fresh root weights (g $100 \mathrm{ml}-1$ ), B: Dry root weights (g $100 \mathrm{ml}-1)$, C: Root growth indexes (Interaction among the L-Phe application and culture duration is not statistically significant) 

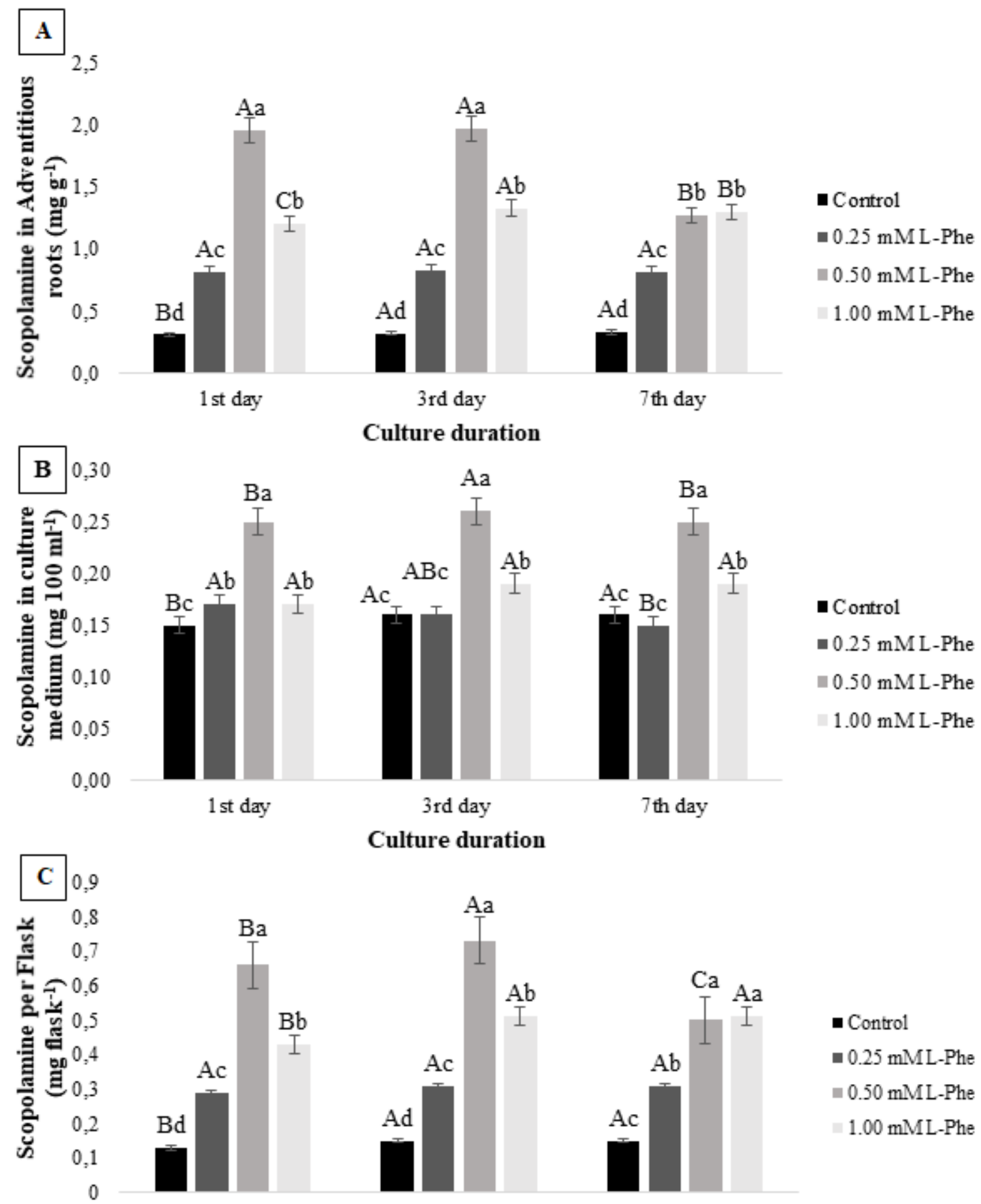

Culture duration

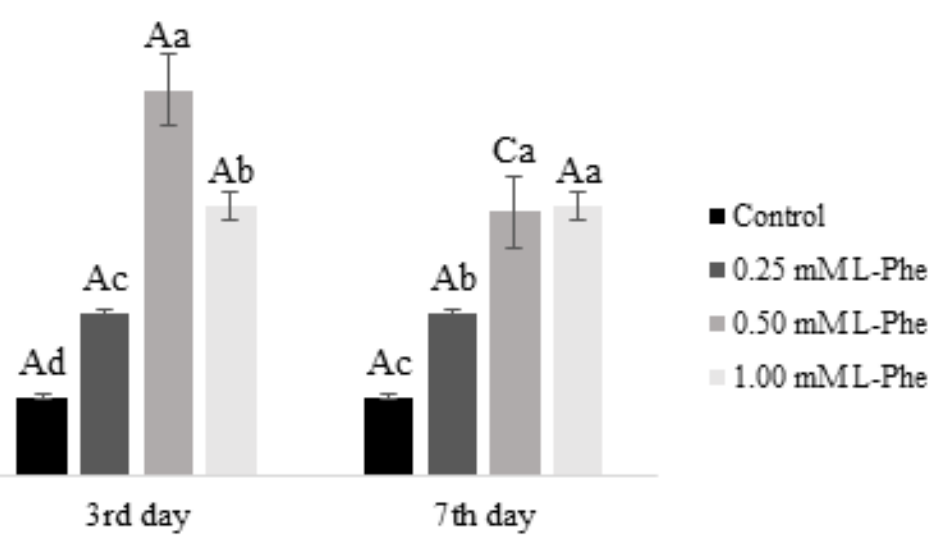

\section{Culture duration}

\section{Figure 3}

Effect of L-Phe and culture duration on scopolamine in adventitious root cultures of Hyoscyamus niger. A: scopolamine in adventitious roots (mg g-1), B: scopolamine in culture medium (mg $100 \mathrm{ml}-1$ ), C: production of scopolamine per flask (mg flask-1) (Differences between culture duration indicated by capital letters; differences between applications indicated by small letters) 

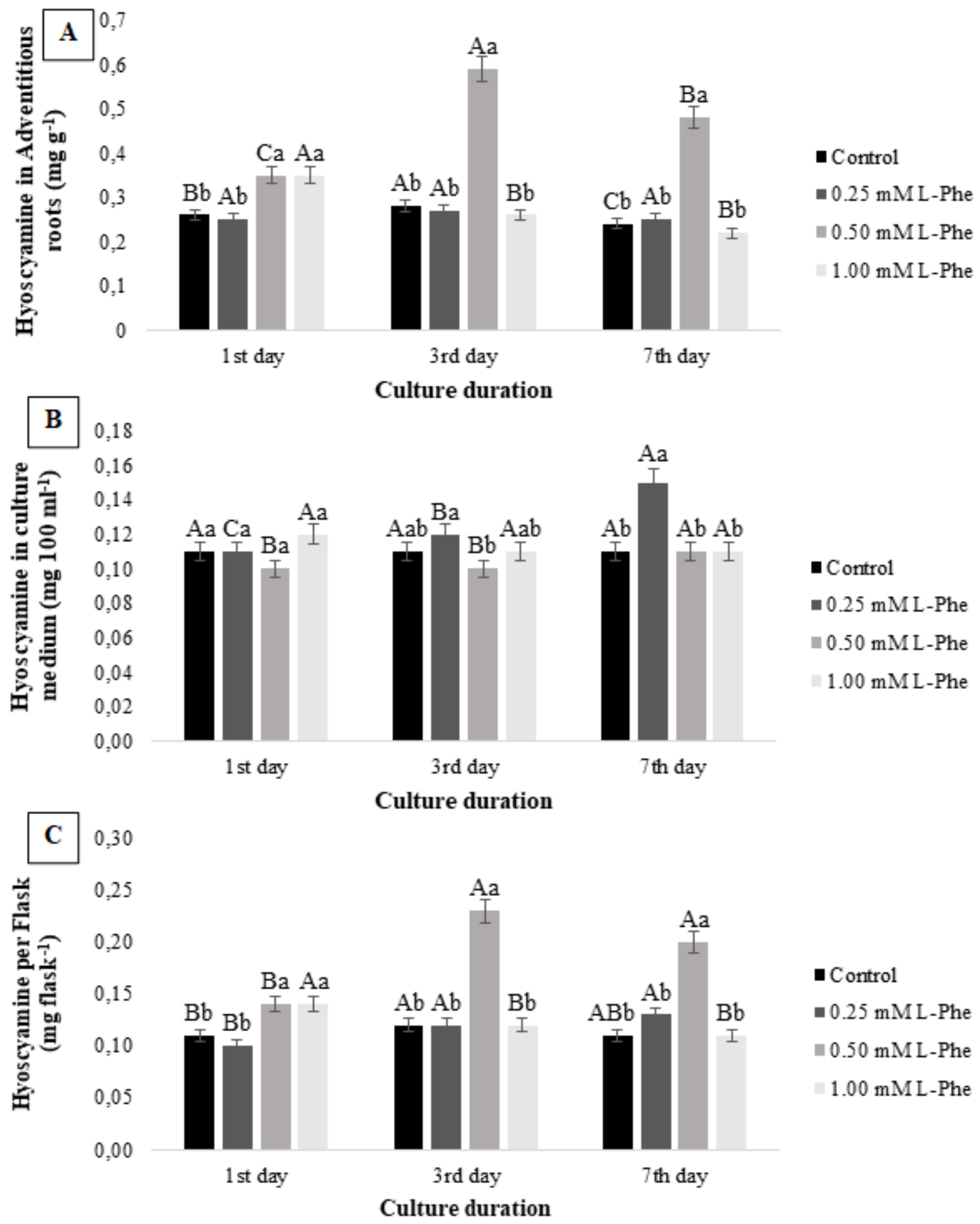

Figure 4

Effect of L-Phe and culture duration on hyoscyamine in adventitious root cultures of Hyoscyamus niger. A: hyoscyamine in adventitious roots (mg g-1), B: hyoscyamine in culture medium (mg $100 \mathrm{ml}-1)$, C: production of hyoscyamine per flask (mg flask-1) (Differences between culture duration indicated by capital letters; differences between applications indicated by small letters) 


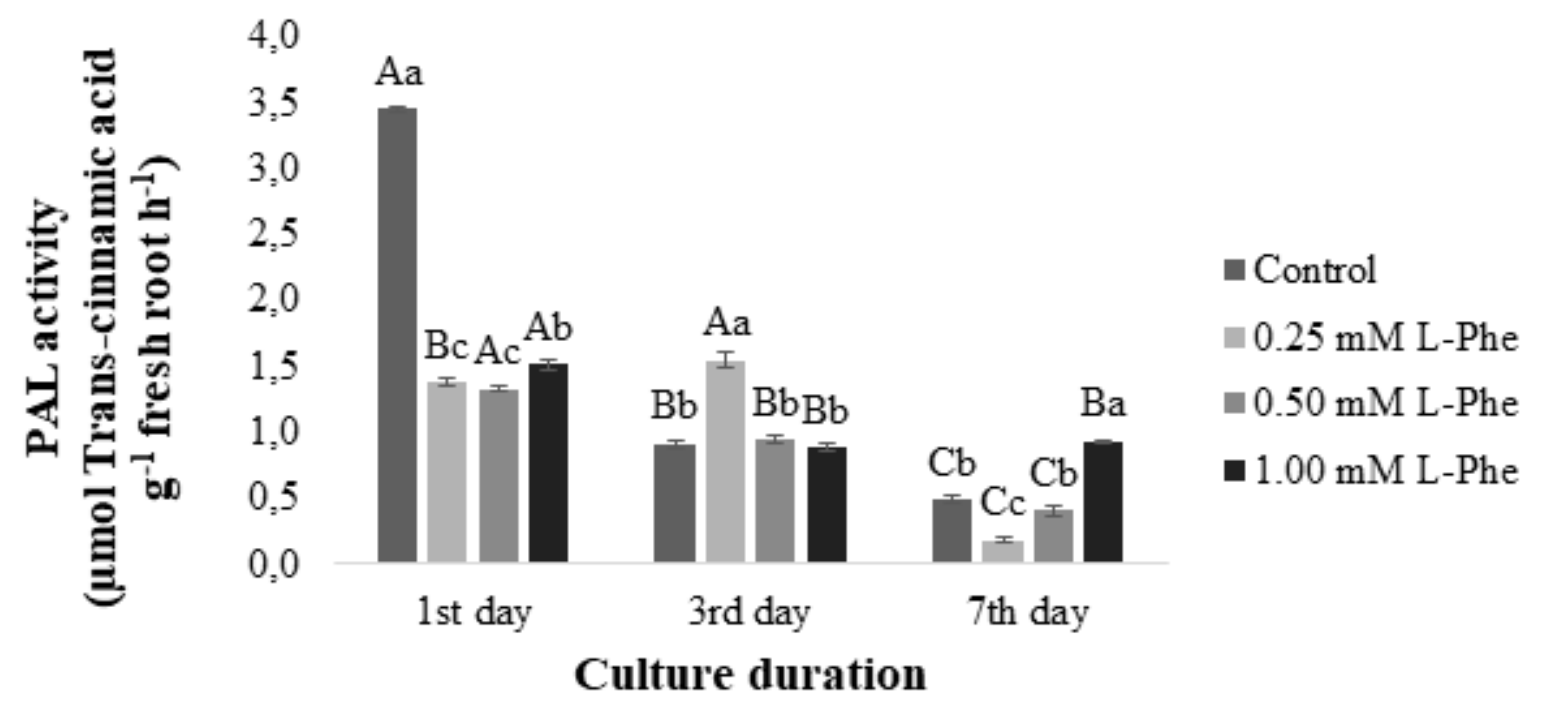

Figure 5

Effect of L-Phenylalanine and culture duration on PAL enzyme activity in adventitious roots of Hyoscyamus niger (Differences between culture duration indicated by capital letters; differences between applications indicated by small letters)

\section{Supplementary Files}

This is a list of supplementary files associated with this preprint. Click to download.

- SupplementaryMaterial1..pdf

- SupplementaryMaterial2..docx 